\title{
Crystal structures of apo and liganded 4-oxalocrotonate decarboxylase uncover a structural basis for the metal-assisted decarboxylation of a vinylogous $\beta$-keto acid
}

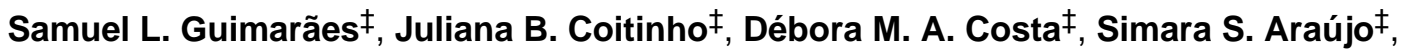 \\ Christian P. Whitman§, and Ronaldo A. P. Nagem $\ddagger$, \\ ‡Departamento de Bioquímica e Imunologia, Instituto de Ciências Biológicas, Universidade \\ Federal de Minas Gerais, Belo Horizonte, 31270-901, Brazil \\ §Division of Chemical Biology and Medicinal Chemistry, College of Pharmacy, The University of \\ Texas, Austin, Texas 78712-1071, United States
}

\begin{abstract}
The enzymes in the catechol meta-fission pathway have been studied for more than 50 years in several species of bacteria capable of degrading a number of aromatic compounds. In a related pathway, naphthalene, a toxic polycyclic aromatic hydrocarbon, is fully degraded to intermediates of the tricarboxylic acid cycle by the soil bacteria Pseudomonas putida G7. In this organism, the $83 \mathrm{~kb}$ NAH7 plasmid carries several genes involved in this biotransformation process. One enzyme in this route, NahK, a 4-oxalocrotonate decarboxylase (4-OD), converts 2-oxo-3hexenedioate to 2-hydroxy-2,4-pentadienoate using $\mathrm{Mg}^{2+}$ as a cofactor. Efforts to study how 4-OD catalyzes this decarboxylation have been hampered because 4-OD is present in a complex with vinylpyruvate hydratase (VPH), which is the next enzyme in the same pathway. For the first time, a monomeric, stable and active 4-OD has been expressed and purified in the absence of VPH. Crystal structures for NahK in apo form and bonded with five substrate analogues were obtained using two distinct crystallization conditions. Analysis of the crystalline structures implicates a lid domain in substrate binding, and suggests roles for specific residues in a proposed reaction mechanism. In addition, we assign a possible function for the NahK N-terminal domain, which differs from most of the other members of the fumarylacetoacetate hydrolase superfamily. Although the structural basis for metal-dependent $\beta$-keto acid decarboxylases has been reported, this is the first structural report for that of a vinylogous $\beta$-keto acid decarboxylase and the first crystal structure of a 4-OD.
\end{abstract}

\section{Graphical Abstract}

\footnotetext{
*Corresponding Author, nagem@ @icb.ufmg.br; Phone: +55 (31) 3409-2626; Fax: Fax: +55 (31) 3409-2614. Author Contributions

RAPN and CPW conceived and designed the experiments; SLG performed the experiments. SLG, JBC, DMAC, SSA, CPW and RAPN analyzed the data and wrote the paper.

Accession numbers

The atomic coordinates and structure factors obtained in this work have been deposited in PDB (PDB entry 5D2F for the apo form of $\mathrm{NahK}$ and entry $5 \mathrm{D} 2 \mathrm{G}$ for the $\mathrm{Mg}^{2+} / \mathrm{NahK}$, entry $5 \mathrm{D} 2 \mathrm{H}$ for the $\mathrm{Mg}^{2+} / \mathrm{a}-$ ketoglutarate/NahK, entry $5 \mathrm{D} 2 \mathrm{I}$ for the $\mathrm{Ca}^{2+} / \mathrm{acetate} / \mathrm{NahK}$, entry $5 \mathrm{D} 2 \mathrm{~J}$ for the $\mathrm{Mg}^{2+} /$ adipate/NahK, and entry $5 \mathrm{D} 2 \mathrm{~K}$ for the $\mathrm{Mg}^{2+} / 2$-oxoadipate/NahK complexes).
} 


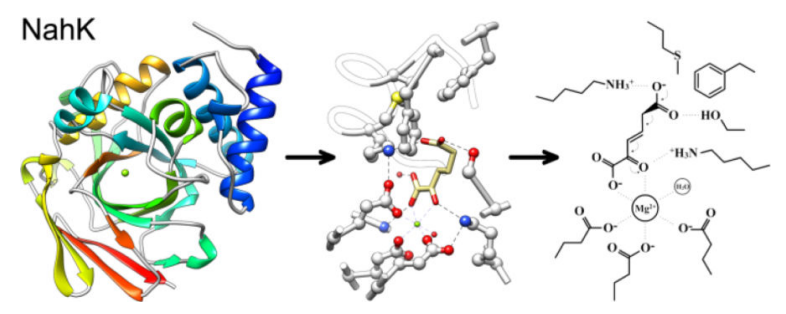

\section{Keywords}

biodegradation; crystal structure; decarboxylase; enzyme mechanism; naphthalene; Pseudomonas putida

\section{INTRODUCTION}

Naphthalene degradation by Pseudomonas putida G7 has been studied extensively since its 83-kilobase plasmid was first isolated ${ }^{(1,2)}$. The NAH7 plasmid carries the catabolic genes (nah) organized in two operons. The gene products encoded by the upper nah operon convert naphthalene (1, Fig 1) to salicylate (2, Fig. 1) and pyruvate, whereas the enzymes encoded by the genes of the lower nah operon process $\mathbf{2}$ to a second pyruvate molecule and acetylCoA. The overall structure and gene organization of the lower pathway of the naphthalene degradation are very similar to those observed in the catechol meta-fission pathways in different Pseudomonas strains, which promote the aerobic degradation of monocyclic aromatic compounds such as benzene, toluene, and xylenes (e.g., the $x y l$ genes of the TOL plasmid pWW0 from $P$. putida mt-2) ${ }^{(3)}$.

In P. putida G7, the fifth reaction in the lower pathway is carried out by NahK, a 4oxalocrotonate decarboxylase (4-OD, EC 4.1.1.77). The enzyme converts a vinylogous $\beta$ keto acid, 2-oxo-3-hexenedioate (3, Fig. 1), to 2-hydroxy-2,4-pentadienoate (4, Fig. 1) and $\mathrm{CO}_{2}$ requiring only a magnesium ion as cofactor. Study of this 4-OD is complicated by the observation that it forms a complex with NahL, a vinylpyruvate hydratase (VPH, EC 4.2.1.80), the next enzyme in the same degradation pathway. A similar observation has been made for XylI and XylJ from P. putida mt-2 ${ }^{(4)}$, which are the NahK and NahL homologues, respectively. VPH then converts 4 to 4-hydroxy-2-oxopentanoate (5, Fig. 1).

The reactions carried out by the 4-OD/VPH complex are interesting and raise mechanistic and structural questions ${ }^{(5-8)}$. Among these questions is the structural basis for both reactions and how 4-OD catalyzes the decarboxylation reaction. A second question is whether the two enzymes have separate active sites where the unstable 4-OD product would be channeled to the VPH active site or a single active site. There are also evolutionary questions. Both enzymes belong to the fumarylacetoacetate hydrolase (FAH) superfamily, which includes MhpD from Escherichia coli K-12 ${ }^{(9)}$, a similar hydratase in the phenylpropionate degradation pathway, and $\mathrm{HpcE}^{(10)}$ and $\mathrm{HpcG}^{(11)}$ from E. coli C, a decarboxylase and hydratase, respectively, in the homoprotocatechuate degradation pathway. NahK and NahL share 39\% sequence identity and likely have the same fold. These observations raise the question of whether a duplication event gave rise to one of the 
enzymes. Thus, for more than 15 years, a different research groups have tried to solve the 3D structure of the 4-OD/VPH complex, but so far without success ${ }^{(12)}$.

Attempts to address these questions in the 4-OD/VPH complex from P. putida mt-2 have been limited by the fact that XylI is unstable in the absence of XylJ $(6,12,13)$. By using NahK from $P$. putida G7, we have now produced a stable 4-OD in large quantities that has similar kinetic parameters to those of 4-OD in the XylI/XylJ native complex.

Crystallographic analysis of the apo form and substrate analogue complexes has uncovered the structural basis for the metal-assisted decarboxylation. In this mechanism, Glu109, Glu111, and Glu142 function as metal binding residues while Lys64, Lys72, and Ser164 play binding and catalytic roles. The side chains of Lys72 and Ser164 position the departing carboxylate group almost perpendicular to the plane of the substrate and place it in front of the hydrophobic side chains of Met76, Phe151 and Phe153. The side chain of Lys64 provides the proton to the dienolate intermediate to form the final dienol product.

This work describes, for the first time, a structural basis for the metal-assisted decarboxylation of a vinylogous $\beta$-keto acid and the first crystal structure of a 4-OD, and sets the stage for future structural studies of the NahK/NahL complex. The results also have implications for the structural diversity of the FAH superfamily as well as the common features.

\section{EXPERIMENTAL PROCEDURES}

\section{Cloning, expression and purification}

The coding sequence of $n a h K$ was amplified from the NAH7 plasmid ${ }^{(2)}$ using the forward primer 5'-GCT-AGC-ATG-AAC-CGT-ACC-CTG-ACC-CGC-3', and the reverse primer 5'AAG-CTT-TCA-GAT-AAA-GCG-CGC-GGA-TAC-CG-3'. The sites for the restriction enzymes NheI and HindII, respectively, are underlined. The amplified PCR fragment was purified, cloned into pGEM-T vector (Promega) and sub-cloned into pET28a-TEV ${ }^{(14)}$. The expression vector was inserted into E. coli BL21(DE3) (Novagen). The correct position and reading frame of the insert was verified by DNA sequencing using $\mathrm{T} 7$ primers in a MegaBACE instrument (GE Healthcare Life Sciences).

For protein production, $20 \mathrm{~mL}$ of LB medium supplemented with $50 \mu \mathrm{g} / \mathrm{mL}$ kanamycin was inoculated with a $n a h K$-transformed clone of E. coli BL21(DE3) and grown at $37{ }^{\circ} \mathrm{C}$ for 16 h. The culture was diluted 1:100 in $2 \mathrm{~L}$ of LB medium supplemented with kanamycin, and grown at $37{ }^{\circ} \mathrm{C}$ until an $\mathrm{OD}_{600}$ of $0.5-0.7$ was reached. The expression was induced with isopropyl $\beta$-D-1-thiogalactopyranoside at $0.5 \mathrm{mM}$, and the cells were grown for an additional $5 \mathrm{~h}$ at $30^{\circ} \mathrm{C}$. After expression, cells were harvested by centrifugation at 5,000 $\times g$ and the pellet was stored at $-20^{\circ} \mathrm{C}$. Prior to cell lysis, the pellet was re-suspended in $40 \mathrm{~mL}$ of lysis buffer ( $20 \mathrm{mM}$ sodium phosphate buffer, $\mathrm{pH} 7.4,500 \mathrm{mM} \mathrm{NaCl}, 45 \mathrm{mM}$ imidazole, and $100 \mu \mathrm{g} / \mathrm{mL}$ lysozyme). Cells were lysed with three freeze-thaw cycles and sonication carried out in an ice-water bath. Soluble and insoluble fractions were separated by centrifugation at $12,000 \times g$ for $30 \mathrm{~min}$ at $4{ }^{\circ} \mathrm{C}$. 
The soluble fraction was immediately loaded onto a $5 \mathrm{~mL} \mathrm{Ni}^{2+}$ affinity column HisTrap HP (GE Healthcare) previously equilibrated with binding buffer $A$ ( $20 \mathrm{mM}$ sodium phosphate buffer, $\mathrm{pH} 7.4,500 \mathrm{mM} \mathrm{NaCl}$, and $45 \mathrm{mM}$ imidazole). The column was washed with binding buffer $A$ and the protein was recovered using an increasing imidazole gradient obtained with elution buffer $A$ ( $20 \mathrm{mM}$ sodium phosphate buffer, $\mathrm{pH} 7.4,500 \mathrm{mM} \mathrm{NaCl}$, and $500 \mathrm{mM}$ imidazole). The eluted fractions were analyzed by Coomassie blue stained 15\% SDS-PAGE. Fractions containing the recombinant protein were pooled, desalted with a HiPrep 26/10 desalting column (GE Healthcare) previously equilibrated and eluted with the final buffer (50 mM Tris- $\mathrm{HCl}$ buffer, $\mathrm{pH} 7.4$, and $50 \mathrm{mM} \mathrm{NaCl}$ ).

The 6xHis-tag was removed by adding TEV Protease 5\% w/w and $1 \mathrm{mM}$ dithiothreitol (final concentration) directly to the protein solution, and the reaction was carried out for $16 \mathrm{~h}$ at $4{ }^{\circ} \mathrm{C}$. The resulting sample was loaded onto a $5 \mathrm{~mL} \mathrm{Ni}^{2+}$ affinity column HisTrap HP for a second purification step by the procedure described above using binding buffer $B(50 \mathrm{mM}$ Tris- $\mathrm{HCl}$ buffer, $\mathrm{pH} 7.4,50 \mathrm{mM} \mathrm{NaCl}$, and $30 \mathrm{mM}$ imidazole) and elution buffer $B(50 \mathrm{mM}$ Tris- $\mathrm{HCl}$ buffer, $\mathrm{pH} 7.4,50 \mathrm{mM} \mathrm{NaCl}$, and $500 \mathrm{mM}$ imidazole).

The resulting NahK sample was concentrated, whenever required, by ultrafiltration using a Vivaspin sample concentrator (10 kDa MWC, GE Healthcare), and then loaded onto a Superdex 200 10/300 GL column (GE Healthcare) for a final gel-filtration purification step using the final buffer. The peak fractions were pooled and the sample purity was verified by Coomassie blue stained 12-15\% SDS-PAGE. The protein concentration at each purification step was determined from the absorbance at $280 \mathrm{~nm}$ using the appropriate extinction coefficient. The 6xHis-NahK and tag-free NahK molar extinction coefficients $(21,430$ and $19,940 \mathrm{M}^{-1} \mathrm{~cm}^{-1}$, respectively) were estimated from the amino acid composition by the ProtParam tool ${ }^{(15)}$ using the ExPASy Server ${ }^{(16)}$.

\section{Dynamic Light Scattering and Circular Dichroism analysis}

The hydrodynamic radius of NahK molecules and the polydispersity of the purified sample were estimated using dynamic light scattering (DLS) assay performed on a Zetasizer Nano ZS system (Malvern Instruments).

NahK samples were centrifuged at $15,000 \times g$ for $10 \mathrm{~min}$ at $4{ }^{\circ} \mathrm{C}$ prior to any measurement. The final protein concentration for DLS measurements was about $1 \mathrm{mg} / \mathrm{mL}$ in final buffer. Each sample was measured in a $10 \mathrm{~mm}$ path length quartz cuvette at $25^{\circ} \mathrm{C}$. Data were collected and analyzed using the Malvern Zetasizer software v. 6.01, where the "Protein Utility" routine was used to estimate particle mass based on the hydrodynamic radius.

The secondary structure content of NahK and its thermal stability were analyzed in a circular dichroism (CD) spectroscopy assay with a Jasco J-815 spectropolarimeter (Jasco Corporation). The final protein concentration for CD measurements was $0.2 \mathrm{mg} / \mathrm{mL}$ in buffer containing $5 \mathrm{mM}$ Tris-HCl pH 7.4 and $5 \mathrm{mM} \mathrm{NaCl}$. Far UV CD spectra (190-260 $\mathrm{nm}$ ) were collected using quartz cuvettes ( 1 or $0.5 \mathrm{~mm}$ path length) in the temperature range 20 to $80{ }^{\circ} \mathrm{C}$ (at $10{ }^{\circ} \mathrm{C}$ intervals). Deconvolution of $\mathrm{CD}$ spectra was performed using the software CDNN v.2.1 ${ }^{(17)}$. 


\section{Kinetic assays}

The NahK decarboxylation activity at $25^{\circ} \mathrm{C}$ was monitored by following the rate of appearance of the product 2-hydroxy-2,4-pentadienoate at $265 \mathrm{~nm}\left(\varepsilon=7,850 \mathrm{M}^{-1} \mathrm{~cm}^{-1}(12)\right)$ in an Agilent $8453 \mathrm{UV}$-Vis spectrophotometer (Agilent Technologies). The reaction mixtures consisted of $20 \mathrm{mM}$ sodium phosphate buffer in the $\mathrm{pH}$ range $6-8,5 \mathrm{mM} \mathrm{MgCl}_{2}$, and 0.5 $\mu \mathrm{g} / \mathrm{mL}$ of $\mathrm{NahK}$. The reaction was initiated by addition of the substrate $(1.6-48.0 \mu \mathrm{M})$ in a final reaction volume of $1.0 \mathrm{~mL}$. The stock solution of substrate (2-oxo-3-hexenedioate) was generated enzymatically by the action of 4-oxalocrotonate tautomerase $\left(\mathrm{XylH}^{(6)}\right)$ on 2hydroxymuconate. The 2-hydroxymuconate was previously dissolved in ethanol then made up in $20 \mathrm{mM}$ sodium phosphate buffer $\mathrm{pH}$ 7.4. The $V_{\max }$ and $K_{\mathrm{M}}$ values, and their standard errors, were estimated by non-linear regression of the initial rate of the reactions versus the concentration of the substrate to the Michaelis-Menten equation using the software GraFit (Erathicus Software Ltd., Staines, U.K.).

\section{Crystallization, data collection, and structure determination}

Pure and monodisperse protein samples were concentrated to approximately $10-12 \mathrm{mg} / \mathrm{mL}$ using a Vivaspin sample concentrator (10 kDa MWC, GE Healthcare), and then used in crystallization trials with sparse-matrix screens $(18)$ at $18^{\circ} \mathrm{C}$. The hanging-drop vapordiffusion method was used and 98 precipitant solutions from Crystal Screen 1 and 2 crystallization kits (Hampton Research) were tested. Crystallization drops consisting of 1 or $2 \mu \mathrm{L}$ of protein solution mixed with $1 \mu \mathrm{L}$ of each screening solution were equilibrated against $1 \mathrm{~mL}$ reservoir of the same screening solution. Conditions where protein crystals formed were manually optimized by grid screening of the precipitant concentration and $\mathrm{pH}$ of the crystallization conditions.

NahK crystals obtained from crystallization conditions were harvested from the crystallization drop with a nylon loop, and immersed for a few seconds into a cryo-cooling solution (reservoir solution with $10 \% \mathrm{v} / \mathrm{v}$ ethylene glycol final concentration). Protein-ligand complexes were obtained by soaking different ligands (6-9, Fig. 1) into apo crystals. The $\mathrm{Mg}^{2+} / \mathrm{NahK}$ and $\mathrm{Mg}^{2+} / \mathrm{a}-\mathrm{ketog}$ lutarate/NahK complexes were obtained when apo crystals were immersed for almost one minute into a cryo-cooling solution containing $0.4 \mathrm{M} \mathrm{MgCl}_{2}$ and/or $0.2 \mathrm{M} \mathrm{a-ketoglutarate.} \mathrm{Alternatively,} \mathrm{a} \mathrm{solution} \mathrm{containing} 100 \mathrm{mM} \mathrm{MgCl}_{2}$ and 15 $\mathrm{mM}$ of adipate or 2-oxoadipate was added to the crystallization drop (after crystal growth) for the $\mathrm{Mg}^{2+}$ /adipate/ $\mathrm{NahK}$ and $\mathrm{Mg}^{2+} / 2$-oxoadipate/NahK complexes, respectively. The $\mathrm{Ca}^{2+} /$ acetate/NahK complex was obtained using only the screening solution in the crystallization trials. Once prepared, all crystals were flash-cooled to $100 \mathrm{~K}$ in a cold nitrogen stream prior to data collection.

In total, six X-ray diffraction data sets were collected at the Laboratório Nacional de Luz Síncrotron (LNLS, Campinas-SP, Brazil). Four of them were collected on a MarCCD 165 mm detector at the D03B-MX1 beamline ${ }^{(19)}$ while two were collected on a MarMosaic 225 $\mathrm{mm}$ detector at the W01B-MX2 beamline ${ }^{(20)}$. All data sets were processed using the HKL-2000 software ${ }^{(21)}$. The crystal structures of NahK and the NahK complexes were solved by the molecular replacement (MR) method using the software Phaser from the CCP4 package ${ }^{(22,23)}$. The template structure used for MR was a single monomer of the $E$. 
coli hydratase HpcG (PDB entry 2EB4), an enzyme which shares $41 \%$ amino acid sequence identity with NahK. Preliminary model building was performed using the software Buccaneer ${ }^{(24)}$. Cycles of structure refinement and manual model adjustments were conducted using the graphical interface of phenix.refine within the PHENIX package ${ }^{(25)}$ and Coot ${ }^{(26)}$, respectively.

\section{RESULTS AND DISCUSSION}

\section{Recombinant NahK is soluble and stable in the absence of NahL}

In 1989, it was reported that XylI is physically associated with XylJ (a 4-OD and a VPH from TOL plasmid pWW0 present in P. putida mt-2), which share 94 and $90 \%$ sequence identity with NahK and NahL, respectively ${ }^{(4)}$. In the same work, the authors expressed XylI in E. coli BL21(DE3) in the absence of XylJ, and partially purified the enzyme by anionexchange chromatography and ammonium sulfate precipitation. This separately expressed and partially purified XylI showed low 4-OD activity, and the activity could not be recovered after passage through a hydrophobic interaction chromatography column. The partially purified XylI rapidly lost activity when concentrated or stored at $4{ }^{\circ} \mathrm{C}$. Attempts to stabilize the enzyme using purification buffers containing $\mathrm{Mg}^{2+}$ and glycerol were also not successful ${ }^{(6,12)}$.

In the present work, we used a different strategy for expression and purification than previously described. The nahK gene from NAH7 plasmid present in P. putida $\mathrm{G} 7$ was subcloned into a pET28a-TEV expression vector and transformed E. coli BL21(DE3) cells were used for protein expression. The expression of the protein was followed by SDS-PAGE analysis (Fig. S1 A1, lanes $0 \mathrm{~h}$ and $5 \mathrm{~h}$ ). The recombinant 6xHis-NahK enzyme was expressed as a partially-soluble molecule (Fig. S1 A1, lanes S and I). The soluble fraction was purified by $\mathrm{Ni}^{2+}$-affinity chromatography, and the 6 xHis-tag was cleaved by recombinant TEV protease. The resulting NahK sample was purified by another $\mathrm{Ni}^{2+}$ affinity chromatography step and the protein was recovered in the flow-through. Subsequently, NahK was purified to homogeneity by size-exclusion chromatography (Fig. S1 A2, lane GF), where the elution volume of the main peak indicated a protein with molecular weight of approximately 25 to $30 \mathrm{kDa}$ (Fig. S1 B), suggesting that NahK behaves as a monomer in solution. Using this methodology a stable form of NahK can be expressed in the absence of NahL. The enzyme can be concentrated and stored at $4{ }^{\circ} \mathrm{C}$ and it retains decarboxylation activity during and after the purification steps.

NahK and Xyll share 94\% amino acid sequence identity where 17 out of 264 amino acid residues are different. Although most of the amino acid substitutions are equivalent in size and/or charge, 15 of them are located on the protein surface with their side chains interacting

Supporting Information

SDS-PAGE analysis of NahK expression and purification (Fig. S1 $A$ ); Size-exclusion chromatography profile of NahK (Fig. S1 $B$ ); Dynamic light scattering measurements of NahK (Fig. S1 C); Secondary structure analysis and thermal stability of NahK by Circular dichroism spectroscopy (Fig. S1 D); Fit of the data to the Michaelis-Menten equation of the measured rates of the decarboxylation at $25^{\circ} \mathrm{C}$ as function of $\mathrm{pH}$ (Fig. S2 A); Ultraviolet-visible spectra for the decarboxylation of 2-oxo-3-hexenedioate by NahK in the absence of NahL (Fig. S2 B); NahK crystals obtained from CS1-16 and CS1-22 conditions (Fig. S3 A/B); X-ray diffraction pattern for the $\mathrm{Mg}^{2+} / 2$-oxoadipate/NahK complex crystal (Fig. S3 C); Video S1 and S2. This material is available free of charge via the Internet at http://pubs.acs.org. 
with the solvent. Thus, despite the high identity, this slight difference between XylI and NahK could be responsible for a higher solubility and stability of NahK compared to XylI. Another possible explanation for this behavior might be the use of a milder purification protocol that does not involve precipitation with ammonium sulfate or hydrophobic interaction chromatography.

\section{Oligomeric state and secondary structure content}

The oligomeric state of NahK was estimated by DLS. The Fig. S1 C presents particle-size distribution by mass, indicating that the sample was mainly composed of a monodisperse particle with $9.7 \%$ of polydispersity, and with a hydrodynamic diameter of $4.7 \mathrm{~nm}$. Mass estimation based on hydrodynamic diameter suggests a protein with molecular weight of approximately $26 \mathrm{kDa}$, indicating that recombinant $\mathrm{NahK}$ behaves as a monomer in solution. This result is in good agreement with the size-exclusion chromatography profile, corroborating the monomeric state of $\mathrm{NahK}$ in solution when expressed as a single component without NahL.

A search in the RCSB Protein Data Bank performed by the DALI server ${ }^{(27,28)}$ using the NahK model obtained in this work identified HpcG (2-oxo-hept-3-ene-1,7-dioate hydratase, PDB entry 2EB4) and MhpD (2-hydroxypentadienoic acid hydratase, PDB entry 2WQT) as the two most similar proteins. They share 41 and $34 \%$ amino acid sequence identity with NahK, respectively. It has been reported that MhpD forms pentamers in solution, while the biological unit of $\mathrm{HpcG}$ is a homodecamer made up of two pentamers similar to MhpD. Since recombinant NahK is a monomer in solution, the presence of NahL would be essential to form any quaternary structure, as observed in XylI and XylJ.

The secondary structure content of NahK was characterized by $\mathrm{CD}$ and confirmed later by the crystal structure. Deconvolution of the data provided an estimated content of $37 \%$ ahelices, $31 \% \beta$-strands, and $31 \%$ random coils (Fig. S1 D). According to the STRIDE server ${ }^{(29)}$, this result is in good agreement with the secondary structure of $\mathrm{HpcG}$ which shows 34\% helical and 32\% $\beta$-strand content, and with MhpD, which shows 32\% a-helices and $31 \% \beta$-strand structures, reflecting the similar folds among these proteins. CD spectra collected at different temperatures suggest $\mathrm{NahK}$ is a relatively stable molecule with a melting temperature between 60 and $70{ }^{\circ} \mathrm{C}$ (Fig. S1 D inset).

\section{Kinetic assays of NahK in the absence of NahL}

Five reaction conditions were examined to determine the effect of $\mathrm{pH}$ on the decarboxylase activity of recombinant NahK. The steady-state kinetic values obtained for each condition are shown in Table 1. Two trends can be seen. First, $K_{\mathrm{M}}$ decreases with increasing $\mathrm{pH}$. This likely reflects the ionization of substrate and its tighter binding (assuming $K_{\mathrm{M}}$ reflects a dissociation constant). It could also result from the titration of the $\mathrm{Mg}^{2+}$-binding residues and the tighter binding of $\mathrm{Mg}^{2+}$. Second, $k_{\mathrm{cat}}$ and $k_{\mathrm{cat}} / K_{\mathrm{M}}$ are highest in the range of 7.08.0. The steady-state kinetic values determined for XylI in the XylI/XylJ complex were $K_{\mathrm{M}}$ $=6.6 \pm 0.6 \mu \mathrm{M}, k_{\mathrm{cat}}=68 \pm 2 \mathrm{~s}^{-1}$, and $k_{\mathrm{cat}} / K_{\mathrm{M}}=1.0 \times 10^{7} \mathrm{M}^{-1} \mathrm{~s}^{-1}$; and for the XylI $/$ E106QXylJ mutant, in which XylJ is devoid of hydratase activity, $K_{\mathrm{M}}=13 \pm 1 \mu \mathrm{M}, k_{\text {cat }}=$ $67 \pm 2 \mathrm{~s}^{-1}$, and $k_{\text {cat }} / K_{\mathrm{M}}=5.1 \times 10^{6} \mathrm{M}^{-1} \mathrm{~s}^{-1}$ (at $\mathrm{pH} 7.3$ and $\left.5 \mathrm{mM} \mathrm{MgCl}_{2}\right)^{(12)}$. Hence, the 
steady-state kinetics parameters for NahK are similar to those obtained for XylI in the XylI/ E106QXylJ complex. These observations suggest that the decarboxylase activity of NahK occurs separately from the NahL-catalyzed reaction. The Michaelis-Menten fit of the data and the ultraviolet-visible spectra for the general reaction catalyzed by NahK are presented in Fig. S2.

\section{Structure determination of NahK and its complexes with substrate analogues}

NahK samples were concentrated and crystallized using the hanging-drop method. After a few days, some nucleation was observed in drops consisting of NahK without the 6xHis-tag in condition \#22 from Crystal Screen 1 crystallization kit (CS1-22: $0.2 \mathrm{M}$ sodium acetate trihydrate, $0.1 \mathrm{M}$ Tris-HCl buffer, $\mathrm{pH} 8.5$, and 30\% w/v PEG 4000). Needle-shaped crystals suitable for diffraction (Fig. S3 A) were grown in a few weeks under optimized conditions derived from CS1-22 with a $\mathrm{pH}$ range from 8.5-10.5, and precipitant concentration of 26$30 \%$. In addition, single rectangular-shaped crystals (Fig. S3 B) were observed after 4 months in drops consisting of 6xHis-NahK in condition \#16 from Crystal Screen 1 crystallization kit (CS1-16: 0.1 M Na HEPES buffer, $\mathrm{pH} 7.5$, and 1.5 M lithium sulfate monohydrate). Crystals from CS1-16 and optimized CS1-22 conditions were used for ligand soaking and in X-ray diffraction experiments.

Three diffraction data sets of crystals obtained in CS1-16 condition were collected (Table 2, data sets 1-3). The first crystal contains the apo-enzyme (Apo model, $1.74 \AA$ A resolution), the second crystal was immersed into a soaking solution containing magnesium ions ( $M g$ model, $1.90 \AA$ ̊ resolution), and the third crystal was soaked in the magnesium solution and then soaked in a solution with a-ketoglutarate ( $A K G$ model, $1.94 \AA$ resolution). These crystals belong to the orthorhombic $P 2_{1} 2_{1} 2_{1}$ space group with average unit-cell parameters of $a=43.4, b=45.0, c=125.0 \AA$. MR for all these data sets was performed successfully using one molecule of $\mathrm{HpcG}$ as the search model.

Three other data sets were collected using NahK crystals grown in the optimized CS1-22 condition (Table 2, data sets 4-6). The first data set refers to a crystal in which an acetate ion was observed in the catalytic site of the enzyme ( $A C T$ model, $1.78 \AA$ resolution), the second one is from a crystal soaked with magnesium and adipate ( $A A$ model, $1.72 \AA$ resolution), while the last data set was collected with a crystal soaked with magnesium and 2-oxoadipate (2OA model, $1.57 \AA$ resolution). These crystals belong to the monoclinic $P 2_{1}$ space group with average unit cell parameters of $a=78.5, b=44.2, c=80.8 \AA, \beta=118.6^{\circ}$. MR using a single monomer of $\mathrm{HpcG}$ as the search model yields two best solutions and both were used to construct the NahK/ligand models.

The final models display a good geometry with an average root-mean-square deviation (rmsd) of $0.007 \AA$ for bond lengths and $1.14^{\circ}$ for angles. On average, considering all polypeptide chains in the six structures, $96.6 \%$ (255/chain) and 3.0\% (8/chain) of the amino acid residues are located in the favored and allowed regions of the Ramachandran plot, respectively. 


\section{Overall structure of NahK}

NahK is a member of the FAH superfamily. Initially, the crystal structure of the mouse FAH was solved (PDB entry 1QCN ${ }^{(30)}$ and described as having a unique fold, which is conserved from bacteria to mammals and defined the overall scaffold of the family. The FAH superfamily has grown considerably since this first report and now includes several other proteins with diverse enzymatic functions such as hydrolysis ${ }^{(31)}$, isomerization ${ }^{(10)}$, dehydration ${ }^{(32)}$, hydration ${ }^{(9,11)}$, and decarboxylation ${ }^{(10,33)}$.

The FAH superfamily scaffold comprises two main domains; the $\mathrm{N}$ - and C-terminal domains. The amino-terminal domain (NTD), consisting of the first 120 amino acid residues, is characterized by an $\alpha / \beta$-sandwich structure. The carboxy-terminal domain (CTD), made up of the last 300 residues, is divided into a barrel-like (incomplete $\beta$-barrel) and a $\beta$-sheet structure. Despite the very low sequence identity between NahK and mouse FAH (9\% identity), the C-terminal domains show similar folds, which is unique to the FAH superfamily. The major differences are observed in the N-terminal domains. Contrary to the mouse FAH, the NTD of NahK, with only 58 residues, folds into an helical domain composed of one short and two long helices. A topology diagram and a ribbon representation of the overall fold of NahK are shown in Fig. $2 A$ and $B$.

HpcG, MhpD, and probably NahL also share a similar fold with NahK. The NTDs are similar to each other and differ from other FAH members (Fig. 3). A sequence alignment of NahK, HpcG, MhpD and NahL is shown in Fig. 4 A. Interestingly, while MhpD is a homopentamer in solution and $\mathrm{HpcG}$ is a dimer of homopentamers, NahK adopts a monomeric form. NahK might only assemble into a complex in the presence of NahL. As previously reported for $\mathrm{HpcG}$ and $\mathrm{MhpD}$, the NTDs are not involved in oligomerization. They face the solvent without any contacts with neighboring chains. This observation suggests that the NTDs of NahK and NahL are not involved in NahK/NahL complex assembly. We propose that the NTD of NahK is involved in the stabilization of the barrellike structure in the CTD through interactions between several residues from the $\beta$-barrel (located in strand 2, helices E and H, and loop 6H) and the NTD. Hydrogen bonds and hydrophobic interactions are responsible for a buried surface area of 1,325 $\AA^{2}$ between these domains. Thus, in contrast to what has been proposed for $\mathrm{HpcG}^{(11)}$, deletion of the NahK NTD might destabilize the incomplete $\beta$-barrel and compromise the folding and activity of NahK. As we have observed, residues adjacent to helix H (in the $\beta$-barrel) compose the loop which forms the entry of the active site and adopts different conformations upon ligand binding - suggesting that destabilization of this region would decrease (or eliminate) the enzyme activity. Even with small differences in some surface loops around their active sites, it is possible to superpose $\mathrm{HpcG}$, MhpD, and NahK monomers $\left(246 \mathrm{C}^{\mathrm{a}}\right.$ atom pairs superposed) with a rmsd close to $1.3 \AA$. The superposed $\mathrm{C}^{\mathrm{a}}$ traces are shown in Fig. 4 B.

A complete survey of all available crystal structures of FAH superfamily members, excluding $\mathrm{HpcG}$ and $\mathrm{MhpD}$, revealed that they primarily adopt a dimeric form as the quaternary structure in which the incomplete $\beta$-barrel edges of each monomer interacts with each other generating a mean buried surface area of $1,665 \AA^{2}$ (varying from 1,103 to 2,778 $\AA^{2}$ ). As shown in Fig. 3, the equivalent position of the second incomplete $\beta$-barrel in these homodimeric structures is occupied by the NTD of NahK, HpcG and MhpD. This 
observation is consistent with our proposal that these specific NTDs stabilize the barrel and allow a different quaternary arrangement in the superfamily.

In the MhpD homopentamer, helices $\mathrm{G}$ and $\mathrm{L}$ (using the NahK nomenclature) in the CTD provide the amino acid residues forming the interface between monomers. In the HpcG homodecamer, these same interactions are observed within each pentamer. In addition, the dimer of pentamers is constructed primarily by interactions between the $\beta$-sheet structures (CTD) present in each ring.

The similar fold of NahK and $\mathrm{HpcG}$, and the sequence identity between NahK and NahL raise the possibility that $\mathrm{NahK}$ and $\mathrm{NahL}$ might interact like the subunits of $\mathrm{HpcG}$ (homodecamer) to form a heterodecamer structure. If so, the $\beta$-sheets at the CTD of NahK and NahL would be involved in oligomerization. To the best of our knowledge, this $280 \mathrm{kDa}$ heterodecamer $(5 \times \mathrm{NahK}+5 \times \mathrm{NahL})$ has never been proposed, although results first obtained in 1973 suggest such a possibility ${ }^{(5)}$. Collinsworth and colleagues obtained a 287 kDa native complex from $P$. putida (determined by analytical ultracentrifugation) that was only tested for VPH activity. Even though they observed two protein bands in a SDSpolyacrylamide gel ( 27.6 and $28.0 \mathrm{kDa}$ each), they believed both bands were derived from the same VPH enzyme, suggesting its native form was composed of 10 subunits. In 1989, an equivalent complex from $P$. putida $\mathrm{mt}-2$ was reported that showed 4-OD and VPH activities and two bands in the SDS-PAGE were also observed (27 and $28 \mathrm{kDa}$ ). However, gel filtration chromatography results were not conclusive about the size of the complex because a value of $130 \mathrm{kDa}$ was obtained ${ }^{(4)}$ and the previous $287 \mathrm{kDa}$ value obtained by Collinsworth was never explored.

A superposition of all NahK models obtained in this work results in a rmsd of $0.55 \AA$ between $\mathrm{C}^{\mathrm{a}}$ atom pairs, with residues from helix $\mathrm{D}$ and loop $6 \mathrm{H}$ (between strand 6 and helix $\mathrm{H}$; residues 149-154) displaying the highest values up to $9.5 \AA$. These residues are located at the sides of the cavity that lead to the active site and could be subjected to conformational changes upon ligand binding. In addition, the same residues have the highest B-factors among the other surface residues of the protein, confirming their predisposition to a greater mobility. Not surprisingly, the same regions in $\mathrm{HpcG}$ and $\mathrm{MhpD}$ also have the highest Bfactors or are not visible in the models.

\section{The active site of NahK}

4-OD is a metal-dependent enzyme requiring magnesium ion for activity. Johnson and colleagues identified conserved and potential catalytic residues in XylI and homologues, and constructed XylI mutants that were expressed and purified as a complex with XylJ (VPH) ${ }^{(13)}$. Two mutants (E109Q and E111Q) lacked the decarboxylase activity of 4-OD, but retained the hydratase activity of VPH. It has been proposed that Glu109 and Glu111 (Xyll or NahK numbering) might be involved in metal binding. The crystallographic model of NahK provides the structural basis for these observations and assigns roles to these and other residues.

In the $A p o$ and $M g$ models the active site is identified as a large cavity approximately $15 \AA$ deep and $19 \AA$ wide. The bottom of this cavity is located in the top of the barrel-like 
structure (in the CTD). According to the CASTp server ${ }^{(34)}$, this cavity has an average volume of approximately $985 \AA^{3}$. Analysis of the electron density map at the bottom of this cavity in the Apo model shows the presence of three water molecules sharing hydrogen bonds with the side chains of three glutamate residues, with no bound metal (Fig. $5 \mathrm{~A}$ ). However, the $M g$ model clearly shows the incorporation of one $\mathrm{Mg}^{2+}$ at the active site (Fig. $5 B$ ). Three water molecules are still present in this model and together with three oxygen ${ }^{\varepsilon}$ atoms from residues Glu109, Glu111, and Glu142 bind to the metal in an octahedral geometry. One of these water molecules (W1, Fig. $5 \mathrm{~A}$ ) is found in the active sites of all NahK models and is buried among the side chains of the protein. This water molecule is stabilized by hydrogen bonds with the backbone carbonyl oxygen of Met65 (2.6 $)$ ), and the oxygen $^{\varepsilon}$ atoms from glutamates in the active site (2.7-2.9 $\AA$ ). The two other coordinating water molecules (W2 and W3, Fig. $5 A$ )are displaced to allow the binding of a ligand.

In addition to the three acidic residues, the NahK active site is also composed of basic amino acids (Lys64 and Lys72). The nitrogen ${ }^{\zeta}$ atom of Lys64 forms a salt bridge with one oxygen ${ }^{\varepsilon}$ atom of Glu142 (2.6 $\AA$ ) in all models. This same group makes an additional hydrogen bond $(2.8 \AA$ ) with either a coordinating water molecule (W3) or an oxygen atom from the ligand (Fig. $5 C-F$ ). This lysine is conserved in the same position in the active sites and/or amino acid sequences of HpcG, MhpD, and NahL (Lys61, Lys60, and Lys60, respectively; Fig. 4 $A$ ), suggesting it plays a role in catalysis of these metal-dependent enzymes.

Contrary to the conserved Lys64, Lys72 appears to be specific to NahK. While Lys64 interacts with the a-keto acid group of the ligand at the metal binding site, Lys72 is located in the opposite side of the active site cavity, and provides a positively charged group to interact with the vinylogous $\beta$-keto carboxylate group of the ligand. This charged amino acid is replaced by hydrophobic residues in HpcG, MhpD and NahL (Met69, Val68, Val68; respectively) reflecting the different biological substrates.

The $A K G, A C T, A A$, and $2 O A$ models show the ligands a-ketoglutarate, acetate, adipate, and 2-oxoadipate, respectively, in the enzyme active site (Fig. $5 C-F$ ). All these ligands displace at least one coordinating water molecule (W3) to interact with the metal as a monodentate ligand. This interaction occurs between the metal and one oxygen atom of their carboxylate group. In the $2 O A$ model, at least in one of the polypeptide chains, the ligand adopts a bidentate conformation in which the a-keto acid group displaces two water molecules (W3 and W2) to interact with the metal (Fig. 5 F). While one of the oxygen atoms from the first carboxylate group (C-1) interacts with $\mathrm{Mg}^{2+}$, the second one makes hydrogen bonds with the main chain amide of Leu67 (2.9 $⿱$ A) and another water molecule (W4, $2.6 \AA$ ) trapped inside the active site. Due to the inability of NahK to decarboxylate the substrate analogue 2-oxoadipate ( 9 , Fig. 1), the conformation adopted by the $\mathrm{Mg}^{2+} / 2$ oxoadipate/NahK complex could reflect what might happen to the substrate and enzyme just before decarboxylation. A detailed list of polar interactions between ligands and protein residues, metal ion and water molecules in the active site is presented in Table 3.

\section{NahK has a lid domain}

Most protein chains in the NahK models show a large active site cavity with an average volume of $845 \AA^{3}$, which is considered as an open conformation. This conformation is 
obtained either in the presence or absence of a magnesium ion. However, as observed in a few chains, NahK adopts a partially closed and a closed conformation upon ligand binding. In the partially closed conformation, observed in chain A from the $A A$ model, the enzyme has a reduced active site volume of approximately $690 \AA^{3}$ caused by the slight movement of helix D (approximately $1.6 \AA$ ) towards the ligand. This movement allows the side chain of residue Lys 72 to form a salt bridge with one oxygen atom from the second carboxylate group (C-6) of the adipate molecule. In addition, the second oxygen of this carboxylate group shares a hydrogen bond with the oxygen $\gamma$ from Ser164. Interestingly, the movement of helix D causes the rearrangement of the residues Phe151 and Phe153 in loop 6H.

One of the biggest changes in the structure is the movement of helix $\mathrm{D}$ in chain $\mathrm{A}$ of the $2 O A$ model. In this conformation (closed conformation), helix D is moved significantly towards the ligand (maximum distance of $9.5 \AA$ ) and together with loop $6 \mathrm{H}$ fills the rest of the active site cavity, reducing its volume to approximately $232 \AA^{3}$ and shielding the ligand from the aqueous environment. Fig. $6 A$ shows the difference in the positions of helix D and loop $6 \mathrm{H}$ in the open and closed conformations. The 2-oxoadipate ligand lacks a double bond between C-3 and C-4 atoms when compared to 2-oxo-3-hexenedioate (9 and 3, Fig. 1). Thus, being more flexible, this substrate analogue may represent the conformation of the substrate in the active site just before decarboxylation. Among the ligands examined, this was the only one that displaced the second coordinating water molecule (W2) and interacted with the metal in a bidentate mode through two oxygen atoms from the a-keto acid group (Fig. $5 F$ ).

In the closed conformation, helix D brings the side chain of Lys 72 even closer to the ligand, making it possible to form a hydrogen bond with oxygen ${ }^{\varepsilon}$ of Glu109 (2.5 $\AA$ ), and a salt bridge with one oxygen atom from the second carboxylate group (C-6) of the ligand ( $2.8 \AA$ ) (Fig. 6 C). The second oxygen of the $\mathrm{C}-6$ carboxylate group forms a hydrogen bond with the oxygen $\gamma$ from Ser164. In addition to these conformational changes, the side chain of Met76, which also moves towards the ligand, is placed together with Phe151 and Phe153 in the vicinity of the C-6 carboxylate group of the ligand, forming a hydrophobic environment favorable for decarboxylation. These three hydrophobic residues are, in average, $3.3 \AA$ apart from the C-6 carboxylate group of 2-oxoadipate.

The corresponding region of helix D is missing in most crystal structures of FAH superfamily members ${ }^{(10,11,31)}$. However, in models showing the enzyme bound to inhibitors or substrate analogs ${ }^{(30)}$, this region is visible and closes the top of the active site cavity. Therefore, our results reinforce the proposal that this region functions as a lid in FAH superfamily $(32,33)$. The availability of three different conformational states (open, partially closed and closed) for NahK allowed us to simulate what might be the movement of helix D and loop $6 \mathrm{H}$ upon substrate binding, highlighting the coordinate rearrangement of catalytic residues to trap and orientate the substrate in the active site just prior decarboxylation (Video S1 and S2).

\section{The decarboxylation mechanism of NahK}

To date, there are three characterized decarboxylases that belong to the FAH superfamily: 4oxalocrotonate decarboxylase (NahK, XylI and other homologues), 5-oxopent-3-ene-1,2,5- 
tricarboxylate decarboxylase $\left(\mathrm{HpcE}^{(10)}\right)$, and oxaloacetate decarboxylase $\left(\mathrm{Cg} 1458^{(33)}\right)$. Ran and colleagues proposed that $\mathrm{Cg} 1458$ uses a glutamic acid-histidine-water catalytic mechanism to facilitate decarboxylation. Although NahK and $\mathrm{Cg} 1458$ belong to the same superfamily and utilize $\mathrm{Mg}^{2+}$ as a cofactor, NahK lacks the equivalent histidine residue in the catalytic site. Moreover, our structural data suggest that the only water molecules available in the active site of $\mathrm{NahK}$ after lid closing are the coordinating water molecules W1 and W4, and both are too far from C-6 of the substrate to interact with it. HpcE and NahK have very similar substrates, with the only difference being a carboxymethyl group attached to C-5 in HpcE's substrate. However, a catalytic mechanism for HpcE is still unclear. The metal is proposed to only hold the residues of the active site in place and not to play a role in decarboxylation ${ }^{(10)}$.

Various decarboxylation mechanisms have been described. As NahK does not use any cofactor other than a divalent ion, decarboxylation mechanisms dependent on pyridoxal-5'phosphate, biotin, flavin, $\mathrm{NAD}^{+} / \mathrm{NADP}^{+}$, and other cofactors can be excluded ${ }^{(35,36)}$. A Schiff base mechanism for decarboxylation has also been eliminated ${ }^{(6)}$. In 2000, Stanley and colleagues suggested the 4-OD mechanism could proceed in a similar manner to the metal ion catalyzed decarboxylation of oxaloacetate ${ }^{(37)}$, in which the metal ion forms a complex through the a-keto acid group of the substrate and acts as an electron sink to stabilize the enolate intermediate and facilitates the decarboxylation. Taken together with our crystallographic data, we propose the enzymatic reaction mechanism described below and shown in Fig. 7.

In the open conformation of NahK (Fig. $7 A$ ), the substrate is allowed to enter into the large active site cavity, displacing one coordinating water molecule (W3) in order to form a monodentate interaction with the metal through one oxygen atom from the $\mathrm{C}-1$ carboxylate group. In this monodentate conformation, the complex adopts a partially closed conformation in which helix D moves slightly towards the ligand allowing the side chain of Lys72 to form a salt bridge with one oxygen atom from the C-6 carboxylate group of the substrate. The second oxygen atom from this C-6 carboxylate group is stabilized by the side chain of Ser164 (Fig. 7 B). Displacement of a second coordinating water molecule (W2) allows the substrate to form a bidentate interaction with $\mathrm{Mg}^{2+}$ through its a-keto acid group. In this bidentate interaction, the substrate moves deeper into the active site allowing the movement of helix D to the closed conformation. This conformation places Met76, Phe151 and Phe153 in the vicinity of the departing C-6 carboxylate group, which is positioned by residues Lys72 and Ser164 almost perpendicular (approximately $70^{\circ}$ ) to the main plane of the substrate. The hydrophobic environment created by Met76, Phe151 and Phe153 and the geometry adopted by the departing carboxylate group favor decarboxylation. At the same time, the $\mathrm{C}-2$ carbonyl oxygen interacts directly with the metal and the nitrogen ${ }^{\zeta}$ atom of Lys-64, favoring the enolate form of the substrate (Fig. 7 C). The formation of the enolate moves the position of the double bond in the conjugated ketone from C-3/C-4 to C-2/C-3 with the consequent destabilization of the carbon-carbon bond between C-5 and C- 6 atoms, transforming it into a dienolate and resulting in the loss of $\mathrm{CO}_{2}$ (Fig. $\left.7 \mathrm{D}\right)^{(38)}$. Finally, Lys64 donates a proton to the enolate oxygen to form the enol tautomer, which corresponds 
to the product of NahK (Fig. 7 E). The helix D comes back to its open conformation, releasing the products and allowing the enzyme to perform a new catalytic cycle (Fig. 7 F).

\section{CONCLUSION}

In this work we present the successful expression, purification and crystallization of an active 4-OD separately from VPH (NahK and NahL from the NAH7 plasmid, respectively). The secondary structure content of NahK is similar to HpcG and MhpD, and although these enzymes form large quaternary structures, recombinant NahK behaves as a monomer in solution, suggesting the interaction with NahL could be essential to oligomerization. The kinetic parameters confirmed that the activity of NahK does not depend on its assembly with NahL. Moreover, the similarity of the $k_{c a t} / K_{M}$ value to that of XylI in the native XylI/XylJ complex $\left(\sim 10^{7} \mathrm{M}^{-1} \mathrm{~s}^{-1}\right)$ suggests that a NahK/NahL complex formation may not substantially improve the activity of the NahK enzyme, but might be required for correct processing of NahK unstable product by NahL. The apo form of the enzyme and different complexes with substrate analogues were crystallized and X-ray diffraction data sets were collected up to $1.57 \AA$ resolution. This allowed the determination of six three dimensional models of NahK.

A comparison among all available crystal structures of FAH superfamily members revealed that the N-terminal domain of NahK stabilizes the incomplete $\beta$-barrel and allows a different quaternary arrangement for this molecule. Contrary to most FAH superfamily members which adopt a dimeric form, NahK is a monomer in solution and might form a heterodecamer complex $(5 \times \mathrm{NahK}+5 \times \mathrm{NahL})$ with $\mathrm{NahL}$ in a similar arrangement observed for HpcG.

In addition, our results suggest that the enzyme adopts at least three particular conformations (open, partially closed and closed) depending on the type of the ligand and the way it is positioned in the catalytic site. Presumably, the decarboxylation reaction performed by NahK requires that the substrate (with six carbon chain) adopt a bidentate interaction with the metal to move the substrate deeper into the active site and allow a more pronounced movement of helix D and loop 6H. The enzyme adopts a closed conformation that seals off the active site from the outside environment and generates a proper geometry and hydrophobic environment for decarboxylation. The presence of this lid domain seems to be a conserved feature of the FAH superfamily enzymes.

Te enzymatic catalytic mechanism proposed in this work represents a new decarboxylation strategy for the FAH superfamily and is the first one described for a vinylogous $\beta$-keto acid metal dependent decarboxylase. Due to the similarities between NahK and HpcE and their substrates, it is likely that $\mathrm{HpcE}$ uses the same decarboxylation mechanism.

\section{Acknowledgments}

In addition to the funding sources, we would like to thank Dr. Masataka Tsuda and Dr. Masahiro Sota for kindly providing us the $P$. putida G7 strain, Dr. William H. Johnson Jr. for providing 2-hydroxymuconate for kinetic assays, and the Laboratório Nacional de Luz Síncrotron (CNPEM, Campinas, Brazil) for provision of synchrotronradiation facilities. 
Funding Sources

This work was supported by FAPEMIG (EDT-0185-0.00-07 and Rede-170/08), CAPES, CNPq (482173/2010-6), VALE S.A (RDP-00174-10), the National Institutes of Health Grant GM-41239 (USA) and the Robert A. Welch Foundation (F-1334).

\section{Abbreviations}

$\begin{array}{ll}\text { 4-OD } & \text { 4-oxalocrotonate decarboxylase } \\ \text { VPH } & \text { vinylpyruvate hydratase } \\ \text { FAH } & \text { fumarylacetoacetate hydrolase } \\ \text { DLS } & \text { dynamic light scattering } \\ \text { CD } & \text { circular dichroism } \\ \text { MR } & \text { molecular replacement } \\ \text { NTD } & \text { amino-terminal domain } \\ \text { CTD } & \text { carboxy-terminal domain }\end{array}$

\section{REFERENCES}

1. Dunn NW, Gunsalus IC. Transmissible plasmid coding early enzymes of naphthalene oxidation in Pseudomonas putida. J Bacteriol. 1973; 114:974-979. [PubMed: 4712575]

2. Tsuda M, Iino T. Naphthalene degrading genes on plasmid NAH7 are on a defective transposon. Mol Gen Genet. 1990; 223:33-39. [PubMed: 2175388]

3. Harayama S, Rekik M, Wasserfallen A, Bairoch A. Evolutionary relationships between catabolic pathways for aromatics: conservation of gene order and nucleotide sequences of catechol oxidation genes of pWW0 and NAH7 plasmids. Mol Gen Genet. 1987; 210:241-247. [PubMed: 3481421]

4. Harayama S, Rekik M, Ngai KL, Ornston LN. Physically associated enzymes produce and metabolize 2-hydroxy-2,4-dienoate, a chemically unstable intermediate formed in catechol metabolism via meta cleavage in Pseudomonas putida. J Bacteriol. 1989; 171:6251-6258. [PubMed: 2681159]

5. Collinsworth WL, Chapman PJ, Dagley S. Stereospecific enzymes in the degradation of aromatic compounds by Pseudomonas putida. J Bacteriol. 1973; 113:922-931. [PubMed: 4690969]

6. Lian H, Whitman CP. Stereochemical and isotopic labeling studies of 4-oxalocrotonate decarboxylase and vinylpyruvate hydratase: analysis and mechanistic implications. J Am Chem Soc. 1994; 116:10403-10411.

7. Kim S, Kweon OK, Kim Y, Kim CK, Lee KS, Kim YC. Localization and sequence analysis of the phnH gene encoding 2-hydroxypent-2,4-dienoate hydratase in Pseudomonas sp. strain DJ77. Biochem Biophys Res Commun. 1997; 238:56-60. [PubMed: 9299451]

8. Burks EA, Johnson WH, Whitman CP. Stereochemical and isotopic labeling studies of 2-oxohept-4-ene-1,7-dioate hydratase: evidence for an enzyme-catalyzed ketonization step in the hydration reaction. J Am Chem Soc. 1998; 120:7665-7675.

9. Montgomery MG, Coker AR, Taylor IA, Wood SP. Assembly of a 20-nm protein cage by Escherichia coli 2-hydroxypentadienoic acid hydratase. J Mol Biol. 2010; 396:1379-1391. [PubMed: 20053352]

10. Tame JR, Namba K, Dodson EJ, Roper DI. The crystal structure of HpcE, a bifunctional decarboxylase/isomerase with a multifunctional fold. Biochemistry. 2002; 41:2982-2989. [PubMed: 11863436]

11. Izumi A, Rea D, Adachi T, Unzai S, Park SY, Roper DI, Tame JR. Structure and mechanism of $\mathrm{HpcG}$, a hydratase in the homoprotocatechuate degradation pathway of Escherichia coli. J Mol Biol. 2007; 370:899-911. [PubMed: 17559873] 
12. Stanley TM, Johnson WH Jr, Burks EA, Whitman CP, Hwang CC, Cook PF. Expression and stereochemical and isotope effect studies of active 4-oxalocrotonate decarboxylase. Biochemistry. 2000; 39:3514. [PubMed: 10727248]

13. Johnson WH Jr, Wang SC, Stanley TM, Czerwinski RM, Almrud JJ, Poelarends GJ, Murzin AG, Whitman CP. 4-Oxalocrotonate tautomerase, its homologue YwhB, and active vinylpyruvate hydratase: synthesis and evaluation of 2-fluoro substrate analogues. Biochemistry. 2004; 43:10490-10501. [PubMed: 15301547]

14. Carneiro FR, Silva TC, Alves AC, Haline-Vaz T, Gozzo FC, Zanchin NI. Spectroscopic characterization of the tumor antigen NY-REN-21 and identification of heterodimer formation with SCAND1. Biochem Biophys Res Commun. 2006; 343:260-268. [PubMed: 16540086]

15. Gasteiger E, Wilkins MR, Bairoch A, Sanchez JC, Williams KL, Appel RD, Hochstrasser DF. Protein identification and analysis tools in the ExPASy server. Methods Mol Biol. 1999; 112:531552. [PubMed: 10027275]

16. Artimo P, Jonnalagedda M, Arnold K, Baratin D, Csardi G, de Castro E, Duvaud S, Flegel V, Fortier A, Gasteiger E, Grosdidier A, Hernandez C, Ioannidis V, Kuznetsov D, Liechti R, Moretti S, Mostaguir K, Redaschi N, Rossier G, Xenarios I, Stockinger H. ExPASy: SIB bioinformatics resource portal. Nucleic Acids Res. 2012; 40:W597-W603. [PubMed: 22661580]

17. Bohm G, Muhr R, Jaenicke R. Quantitative analysis of protein far UV circular dichroism spectra by neural networks. Protein Eng. 1992; 5:191-195. [PubMed: 1409538]

18. Jancarik J, Kim S-H. Sparse matrix sampling: a screening method for crystallization of proteins. J Appl Crystallogr. 1991; 24:409-411.

19. Polikarpov I, Perles LA, de Oliveira RT, Oliva G, Castellano EE, Garratt RC, Craievich A. Set-up and experimental parameters of the protein crystallography beamline at the Brazilian National Synchrotron Laboratory. J Synchrotron Radiat. 1998; 5:72-76. [PubMed: 16687806]

20. Guimaraes BG, Sanfelici L, Neuenschwander RT, Rodrigues F, Grizolli WC, Raulik MA, Piton JR, Meyer BC, Nascimento AS, Polikarpov I. The MX2 macromolecular crystallography beamline: a wiggler X-ray source at the LNLS. J Synchrotron Radiat. 2009; 16:69-75. [PubMed: 19096177]

21. Otwinowski Z, Minor W. Processing of X-ray Diffraction Data Collected in Oscillation Mode. Method Enzymol. 1997; 276:307-326.

22. McCoy AJ, Grosse-Kunstleve RW, Adams PD, Winn MD, Storoni LC, Read RJ. Phaser crystallographic software. J Appl Crystallogr. 2007; 40:658-674. [PubMed: 19461840]

23. Winn MD, Ballard CC, Cowtan KD, Dodson EJ, Emsley P, Evans PR, Keegan RM, Krissinel EB, Leslie AG, McCoy A, McNicholas SJ, Murshudov GN, Pannu NS, Potterton EA, Powell HR, Read RJ, Vagin A, Wilson KS. Overview of the CCP4 suite and current developments. Acta Crystallogr D Biol Crystallogr. 2011; 67:235-242. [PubMed: 21460441]

24. Cowtan K. The Buccaneer software for automated model building. 1. Tracing protein chains. Acta Crystallogr D Biol Crystallogr. 2006; 62:1002-1011. [PubMed: 16929101]

25. Adams PD, Afonine PV, Bunkoczi G, Chen VB, Davis IW, Echols N, Headd JJ, Hung LW, Kapral GJ, Grosse-Kunstleve RW, McCoy AJ, Moriarty NW, Oeffner R, Read RJ, Richardson DC, Richardson JS, Terwilliger TC, Zwart PH. PHENIX: a comprehensive Python-based system for macromolecular structure solution. Acta Crystallogr D Biol Crystallogr. 2010; 66:213-221. [PubMed: 20124702]

26. Emsley P, Lohkamp B, Scott WG, Cowtan K. Features and development of Coot. Acta Crystallogr D Biol Crystallogr. 2010; 66:486-501. [PubMed: 20383002]

27. Berman HM, Westbrook J, Feng Z, Gilliland G, Bhat TN, Weissig H, Shindyalov IN, Bourne PE. The Protein Data Bank. Nucleic Acids Res. 2000; 28:235-242. [PubMed: 10592235]

28. Holm L, Sander C. Dali: a network tool for protein structure comparison. Trends Biochem Sci. 1995; 20:478-480. [PubMed: 8578593]

29. Frishman D, Argos P. Knowledge-based protein secondary structure assignment. Proteins. 1995; 23:566-579. [PubMed: 8749853]

30. Timm DE, Mueller HA, Bhanumoorthy P, Harp JM, Bunick GJ. Crystal structure and mechanism of a carbon-carbon bond hydrolase. Structure. 1999; 7:1023-1033. [PubMed: 10508789] 
31. Manjasetty BA, Niesen FH, Delbruck H, Gotz F, Sievert V, Bussow K, Behlke J, Heinemann U. Xray structure of fumarylacetoacetate hydrolase family member Homo sapiens FLJ36880. Biol Chem. 2004; 385:935-942. [PubMed: 15551868]

32. Brouns SJ, Barends TR, Worm P, Akerboom J, Turnbull AP, Salmon L, van der Oost J. Structural insight into substrate binding and catalysis of a novel 2-keto-3-deoxy-D-arabinonate dehydratase illustrates common mechanistic features of the FAH superfamily. J Mol Biol. 2008; 379:357-371. [PubMed: 18448118]

33. Ran T, Gao Y, Marsh M, Zhu W, Wang M, Mao X, Xu L, Xu D, Wang W. Crystal structures of Cg1458 reveal a catalytic lid domain and a common catalytic mechanism for the FAH family. Biochem J. 2013; 449:51-60. [PubMed: 23046410]

34. Dundas J, Ouyang Z, Tseng J, Binkowski A, Turpaz Y, Liang J. CASTp: computed atlas of surface topography of proteins with structural and topographical mapping of functionally annotated residues. Nucleic Acids Res. 2006; 34:W116-W118. [PubMed: 16844972]

35. Li T, Huo L, Pulley C, Liu A. Decarboxylation mechanisms in biological system. Bioorg Chem. 2012; 43:2-14. [PubMed: 22534166]

36. O'Leary, MH. The Enzymes: Mechanisms of catalysis. Burkington: Elsevier Science; 1992. Catalytic Strategies in Enzymic Carboxylation and Decarboxylation; p. 235-269.

37. Grissom CB, Cleland WW. Carbon isotope effects on the metal ion catalyzed decarboxylation of oxalacetate. J Am Chem Soc. 1986; 108:5582-5583.

38. Casiraghi G, Zanardi F, Appendino G, Rassu G. The vinylogous aldol reaction: a valuable, yet understated carbon-carbon bond-forming maneuver. Chem Rev. 2000; 100:1929-1972. [PubMed: 11749280]

39. Baugh L, Phan I, Begley DW, Clifton MC, Armour B, Dranow DM, Taylor BM, Muruthi MM, Abendroth J, Fairman JW, Fox D 3rd, Dieterich SH, Staker BL, Gardberg AS, Choi R, Hewitt SN, Napuli AJ, Myers J, Barrett LK, Zhang Y, Ferrell M, Mundt E, Thompkins K, Tran N, LyonsAbbott S, Abramov A, Sekar A, Serbzhinskiy D, Lorimer D, Buchko GW, Stacy R, Stewart LJ, Edwards TE, Van Voorhis WC, Myler PJ. Increasing the structural coverage of tuberculosis drug targets. Tuberculosis (Edinb). 2015; 95:142-148. [PubMed: 25613812]

40. Kube M, Chernikova TN, Al-Ramahi Y, Beloqui A, Lopez-Cortez N, Guazzaroni ME, Heipieper HJ, Klages S, Kotsyurbenko OR, Langer I, Nechitaylo TY, Lunsdorf H, Fernandez M, Juarez S, Ciordia S, Singer A, Kagan O, Egorova O, Petit PA, Stogios P, Kim Y, Tchigvintsev A, Flick R, Denaro R, Genovese M, Albar JP, Reva ON, Martinez-Gomariz M, Tran H, Ferrer M, Savchenko A, Yakunin AF, Yakimov MM, Golyshina OV, Reinhardt R, Golyshin PN. Genome sequence and functional genomic analysis of the oil-degrading bacterium Oleispira antarctica. Nat Commun. 2013; 4:2156. [PubMed: 23877221]

41. Robert X, Gouet P. Deciphering key features in protein structures with the new ENDscript server. Nucleic Acids Res. 2014; 42:W320-W324. [PubMed: 24753421]

42. Pettersen EF, Goddard TD, Huang CC, Couch GS, Greenblatt DM, Meng EC, Ferrin TE. UCSF Chimera--a visualization system for exploratory research and analysis. J Comput Chem. 2004; 25:1605-1612. [PubMed: 15264254] 
<smiles>c1ccc2ccccc2c1</smiles>

1<smiles>O=C([O-])c1ccccc1O</smiles>

2

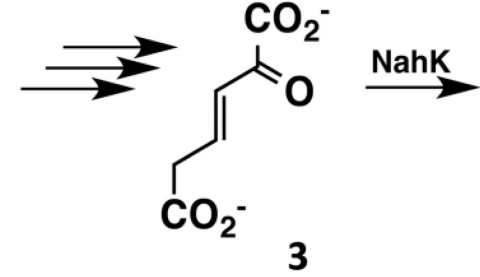

3<smiles>C=C/C=C(\O)C(=O)O[Na]</smiles>

4<smiles>CC(=O)C(=O)O[Na]</smiles><smiles>CC(=O)C(=O)[O-]</smiles><smiles>O=C([O-])CCC(=O)O</smiles><smiles>O=C([O-])CCCCC(=O)[O-]</smiles><smiles>O=C([O-])CCCC(=O)[O-]</smiles>

Figure 1.

Naphthalene-degradation pathway in $P$. putida G7. The upper pathway degrades naphthalene (1) to pyruvate and salicylate (2) using the enzymes NahAaAbAcAdBCDEF. The lower pathway is composed of the enzymes NahGHIJKLMNO and converts 2 to pyruvate and acetyl-CoA. The intermediates, 2-oxo-3-hexenedioate (3), 2-hydroxy-2,4-pentadienoate (4), and 4-hydroxy-2-oxopentanoate (5) are also depicted. Molecules with structures similar to NahK's substrate are shown: acetate (6), a-ketoglutarate (7), adipate (8) and 2-oxoadipate (9). 

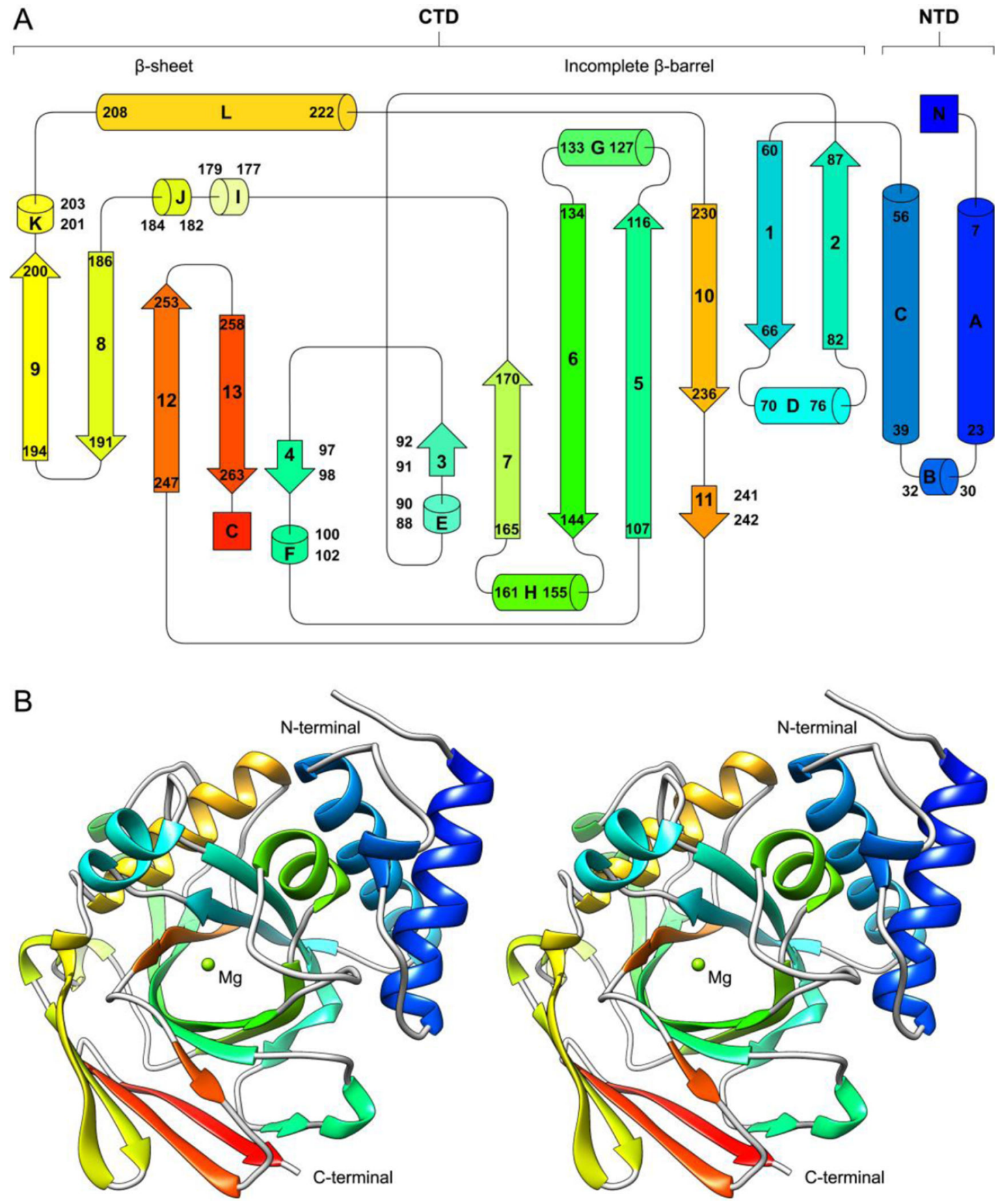

Figure 2.

Different representations of the overall fold of NahK. Topology diagram (A) and a crosseyed stereo cartoon of NahK in complex with magnesium (B). (A) Helices are shown as tubes and labeled alphabetically, and $\beta$-strands are shown as arrows and labeled numerically. Color shades from blue to red represent the progress of the chain from $\mathrm{N}$ to $\mathrm{C}$-terminus. (B) $\mathrm{Mg}^{2+}$ cation (green sphere) bonded to the protein (colored as in $\mathbf{A}$ ) lies at the center of the incomplete $\beta$-barrel structure. 


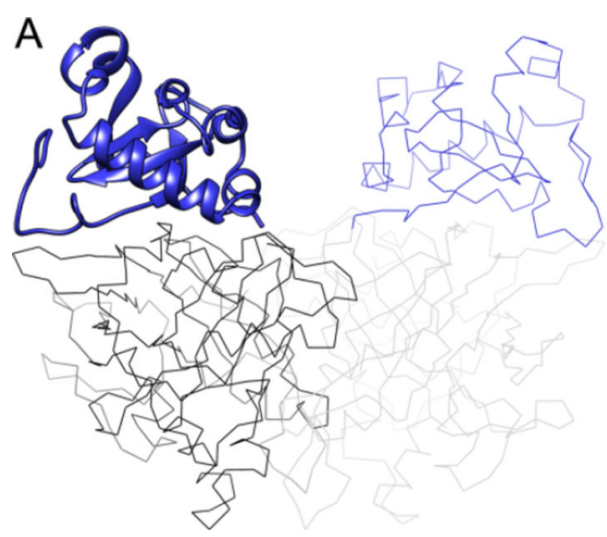

D

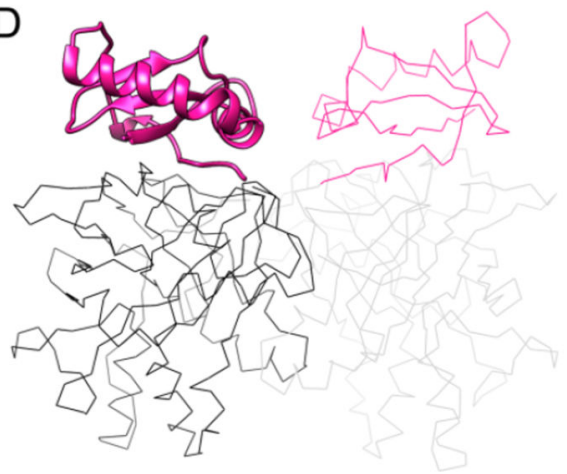

G

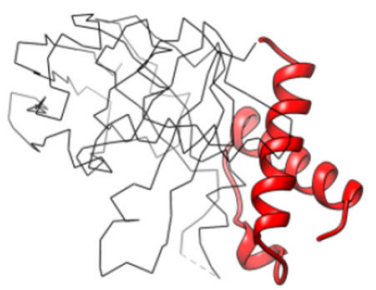

B

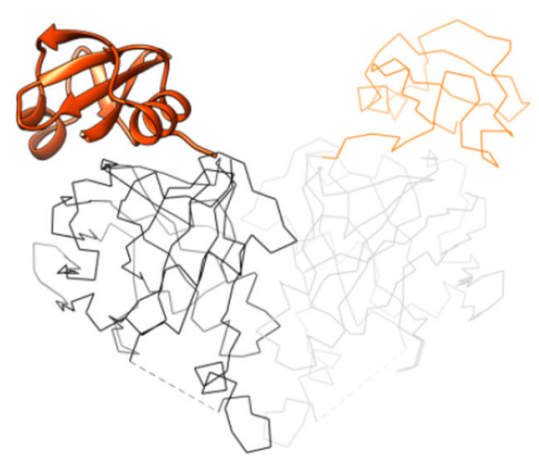

$E$
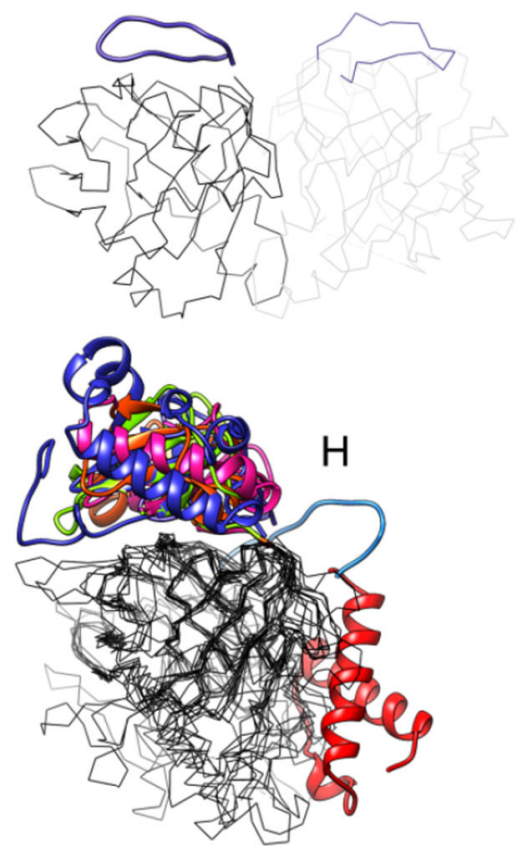

C

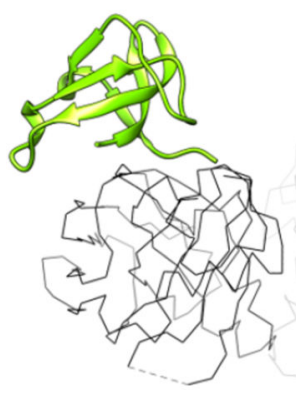

$\mathrm{F}$

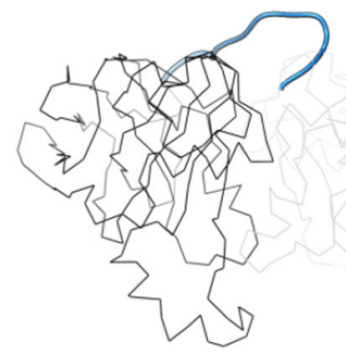

Figure 3.

Comparative analysis of the N-terminal domains of FAH superfamily members. (A-G) All 21 FAH members available in the Protein Data Bank to date were grouped according to the overall structure of their N-terminal domains. Only one member of each cluster (quite often a dimeric protein) was chosen to represent the overall fold of the group. Representative tertiary and quaternary structures of enzymes from (A) Mus musculus (PDB entry $1 \mathrm{QCN}{ }^{(30)}$ and Burkholderia cenocepacia (PDB entry 4QKU); (B) Sulfolobus solfataricus (PDB entry $2 \mathrm{Q} 18^{(32)}$; (C) Mycobacterium marinum (PDB entry 3QDF ${ }^{(39)}$, Thermus thermophilus (PDB entry 2DFU and PDB entry 1WZO), M. abscessos (PDB entry 3RR6 ${ }^{(39)}$, Corynebacterium glutamicum (PDB entry 4DBF ${ }^{(33)}$, and M. smegmatis (PDB entry 4PFZ); (D) M. abscessos (PDB entry 3R6O ${ }^{(39)}$ and Sinorhizobium meliloti (PDB entry $3 \mathrm{LZK})$; (E) Homo sapiens (PDB entry $1 \mathrm{SAW}{ }^{(31)}$, E. coli (PDB entry 1NR9), Yersinia pestis (PDB entry 3S52), Oleispira antarctica (PDB entry 3V77 ${ }^{(40)}$, B. cenocepacia (PDB entry 4MAQ) and Saccharomyces cerevisiae (PDB entry 1NKQ); (F) E. coli HpcE (PDB 
entry $1 \mathrm{GTT}^{(10)}$ and $(\mathbf{G})$ E. coli $\mathrm{HpcG}$ (PDB entry 2EB4 ${ }^{(11)}$, E. coli MhpD (PDB entry $2 \mathrm{WQT}^{(9)}$ and $P$. putida NahK (this work). (H) Superposition of representative monomers showing the conserved CTD (incomplete $\beta$-barrel and $\beta$-sheet) and the position of each NTD. 

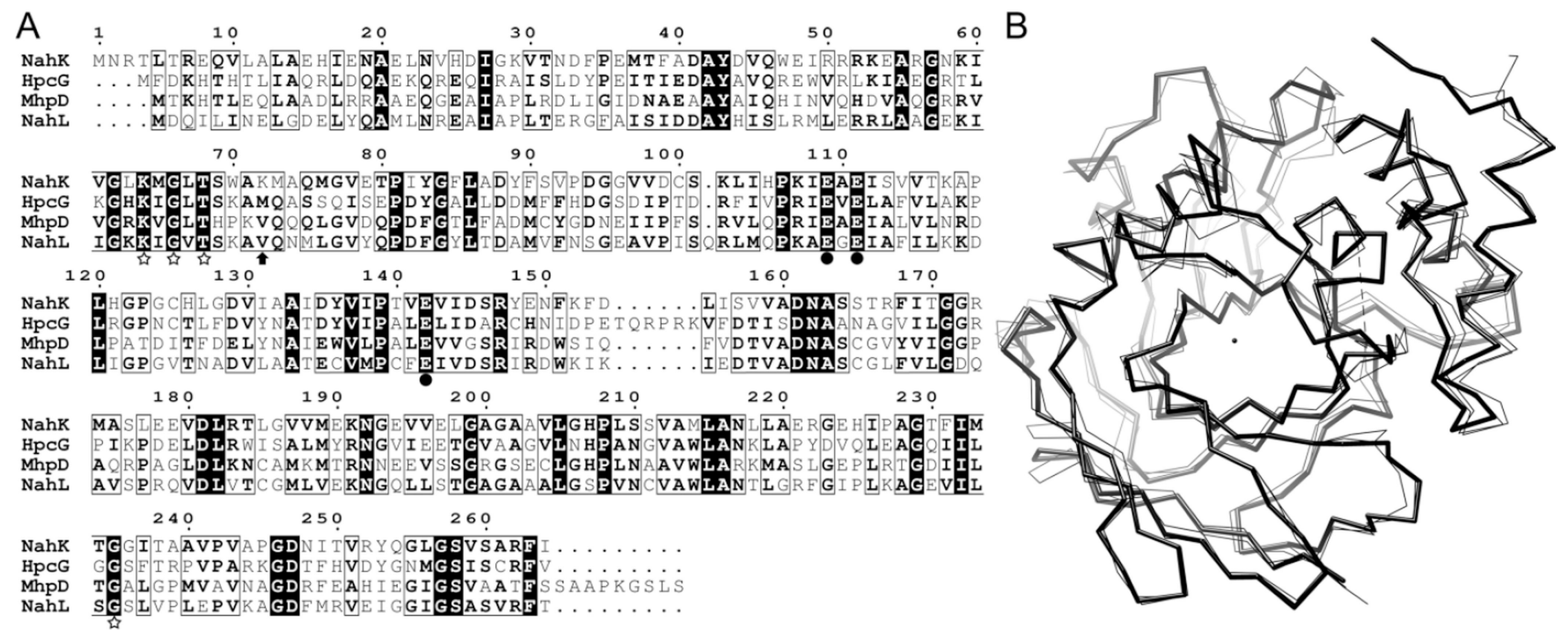

Figure 4.

Multiple alignments between NahK and similar proteins. (A) Sequence alignment of NahK, $\mathrm{HpcG}, \mathrm{MhpD}$, and NahL. The glutamate residues that coordinate the metal ion are indicated with black circles, while other conserved residues at the active site are indicated with a star. Lys72, a specific residue in the catalytic site of NahK, is indicated with an arrow. The Figure was prepared using ESPript 3.0 ${ }^{(41)}$. (B) Superposition of the $\mathrm{C}^{\mathrm{a}}$ backbone of NahK (thickest line) with $\mathrm{HpcG}$ and MhpD (thinnest line). The dot at the center of the structure shows the position of the metal ion. 


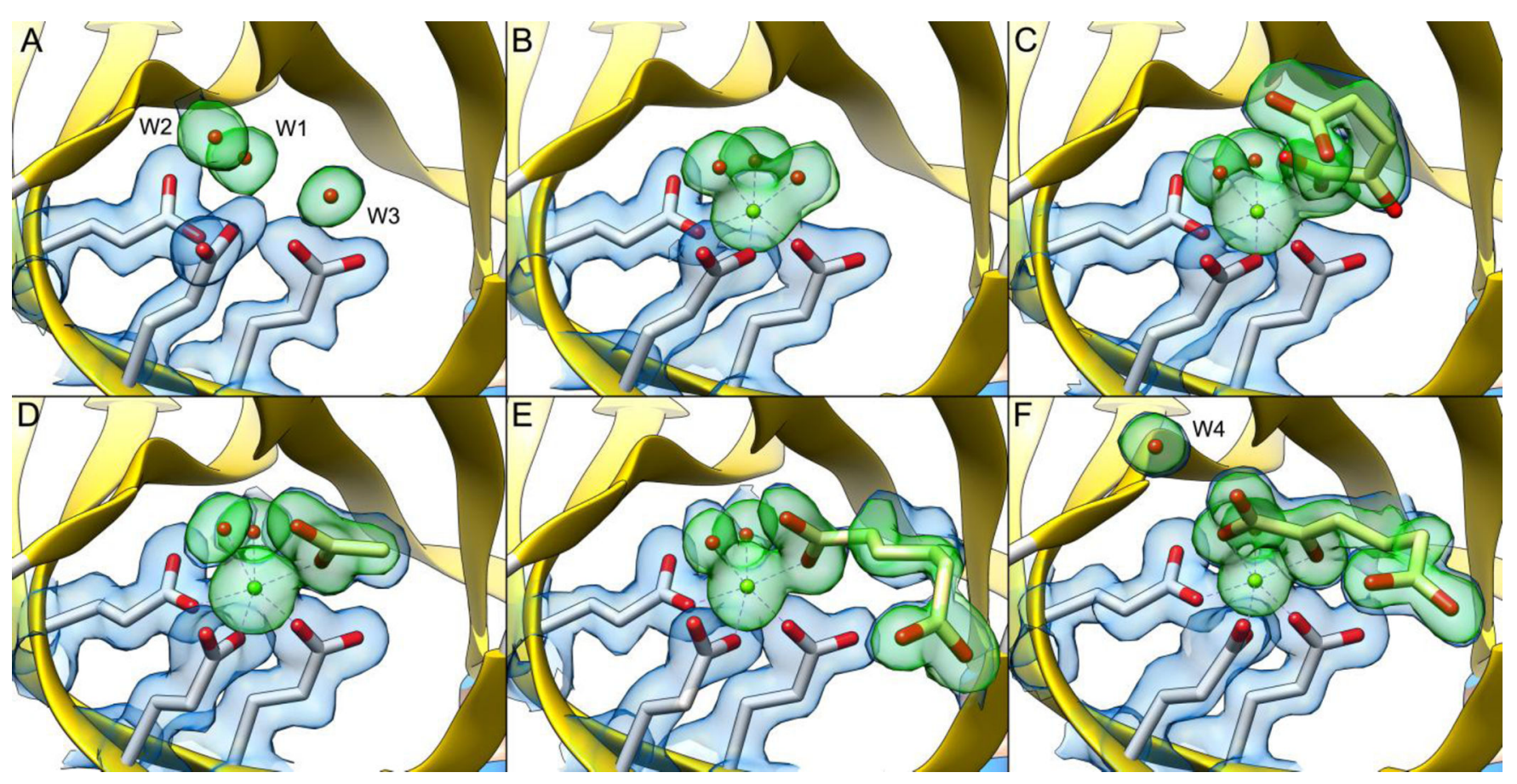

Figure 5.

Electron density maps illustrating the position of metals (green spheres), water molecules (red spheres) and ligands (yellow and red stick-models) at the active site of crystallized NahK. The $2 \mathrm{~F}_{\mathrm{o}}-\mathrm{F}_{\mathrm{c}}$ map (blue) and omit map (green) are contoured at 1.0 and $4.0 \mathrm{\sigma}$ respectively. Water molecules $\mathbf{W 1}, \mathbf{W} \mathbf{2}, \mathbf{W 3}$, and $\mathbf{W} \mathbf{4}$ are named and described in the text. (A) Apo model: active site with the electron density map of three water molecules sharing hydrogen bonds with three glutamate residues. (B) $M g$ model: active site with a magnesium ion coordinated by three glutamate residues and three water molecules. (C) $A K G$ model: in addition to the presence of one magnesium ion, the electron density above the metal suggests the presence of an a-ketoglutarate molecule. Two water molecules also coordinate the metal. (D) ACT model: the electron density suggests the presence of a metal ion being coordinated by the glutamate residues. An acetate ion from the crystallization buffer is also present along with two water molecules coordinating the metal. (E) $A A$ model: the electron density shows that one magnesium ion and one adipate molecule are present in the active site. Two water molecules coordinate the metal. (F) $2 O A$ model: the electron density from a 2-oxoadipate molecule is observed near the magnesium ion. One water molecule (W1; behind the plane of the ligand) is interacting with the metal. 

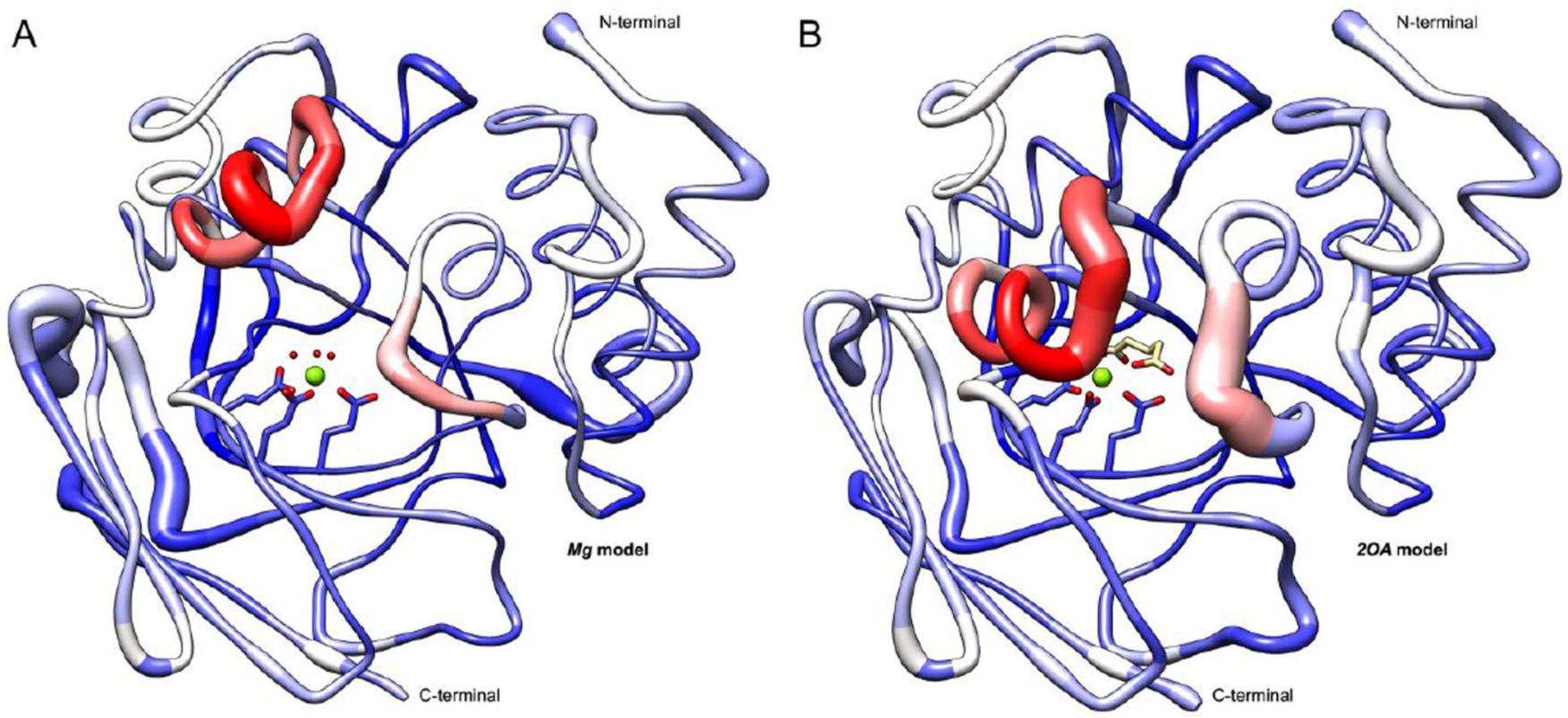

C
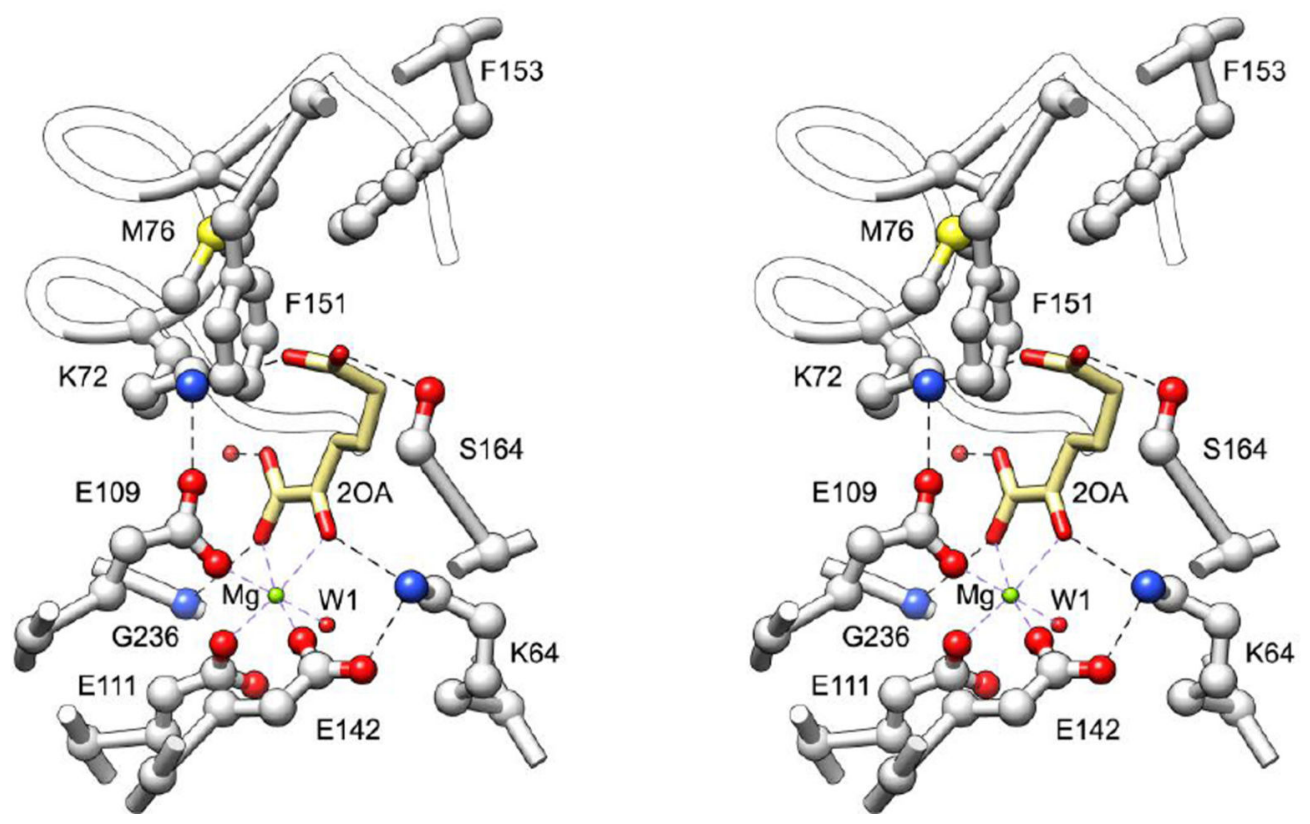

Figure 6.

Conformational changes in NahK upon ligand binding. The open conformation of the $M g$ model (A) and the closed conformation of the $2 O A$ model (B) are depicted as a 'worm' model. The thickness of the chains is proportional to the B-factor values per residue in each model, indicating the parts of the protein with more thermal motion. The color shades from blue (rmsd value of $0.482 \AA$ ), to white (rmsd value of $1.0 \AA$ ), and red (rmsd value of $9.5 \AA$ ) represent the rmsd between $\mathrm{C}^{\mathrm{a}}$ pairs from the two models. Red color shades indicate the parts of the protein with the highest difference between the positions of the $\mathrm{C}^{a}$ pairs. The three glutamate residues coordinating the magnesium ion are shown at the bottom of the active site in both models, and in the $2 \mathrm{OA}$ model (B) the 2-oxoadipate molecule is 
represented as a stick model. (C) A cross-eyed stereo representation of the catalytic site of the $\mathrm{Mg}^{2+} / 2$-oxoadipate/NahK complex in the closed conformation is shown. Main hydrogen bonds, salt bridges, and metal coordination are represented by dashed lines. Helix D composing the lid domain is depicted as a helical tube. The a-keto acid moiety of 2oxoadipate binds to $\mathrm{Mg}^{2+}$ in a bidentate mode, while the second carboxylate group is positioned $70^{\circ}$ outside the plane of the ligand, making it almost parallel to the $\pi$-orbitals of the vinylogous ketone. The departing carboxylate group could be positioned in this conformation by Lys72 and Ser164. The hydrophobic residues Met76, Phe151 and Phe153 which might facilitate decarboxylation of the substrate are also shown. The Figures were prepared using Chimera software ${ }^{(42)}$. 


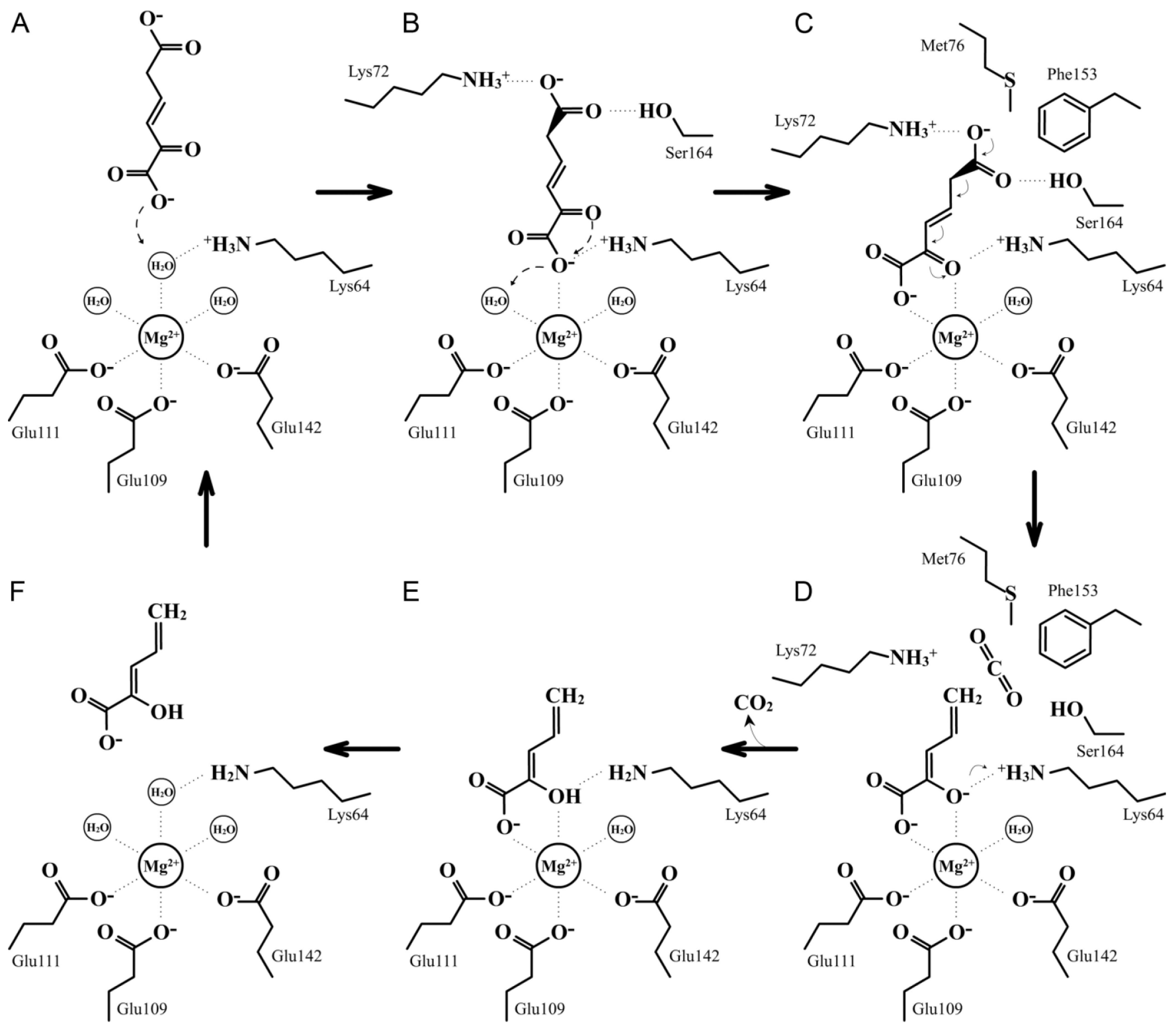

Figure 7.

Proposed decarboxylation mechanism for NahK. The (A) open, (B) partially closed and (CD) closed conformations of the substrate/enzyme complex are presented with major catalytic residues. (D) Decarboxylation of the dienolate form of the intermediate takes place in the catalytic site with a subsequent $(\mathbf{E})$ formation of the dienol form of the product. (F) The product is released from the enzyme catalytic site allowing a new decarboxylation cycle to occur. 


\section{Table 1}

Variation of the steady-state kinetics of NahK with $\mathrm{pH}$.

\begin{tabular}{|l|l|l|l|}
\hline $\mathbf{p H}$ & $\boldsymbol{K}_{\mathbf{M}}(\boldsymbol{\mu M})$ & $\boldsymbol{k}_{\text {cat }}\left(\mathbf{s}^{\mathbf{- 1}}\right)$ & $\boldsymbol{k}_{\mathrm{cat}} / \boldsymbol{K}_{\mathbf{M}}\left(\mathbf{M}^{\mathbf{- 1}} \mathbf{s}^{\mathbf{- 1}}\right)$ \\
\hline $\mathbf{6 . 0}$ & $51.7 \pm 14.2$ & $22.5 \pm 4.1$ & $4.4 \times 10^{5}$ \\
\hline $\mathbf{6 . 5}$ & $64.7 \pm 8.5$ & $108.4 \pm 9.8$ & $1.7 \times 106$ \\
\hline $\mathbf{7 . 0}$ & $22.2 \pm 2.4$ & $104.2 \pm 5.5$ & $4.7 \times 10^{6}$ \\
\hline $\mathbf{7 . 4}$ & $19.9 \pm 1.1$ & $98.8 \pm 2.7$ & $5.0 \times 10^{6}$ \\
\hline $\mathbf{8 . 0}$ & $4.9 \pm 0.3$ & $21.8 \pm 0.3$ & $4.5 \times 10^{6}$ \\
\hline
\end{tabular}




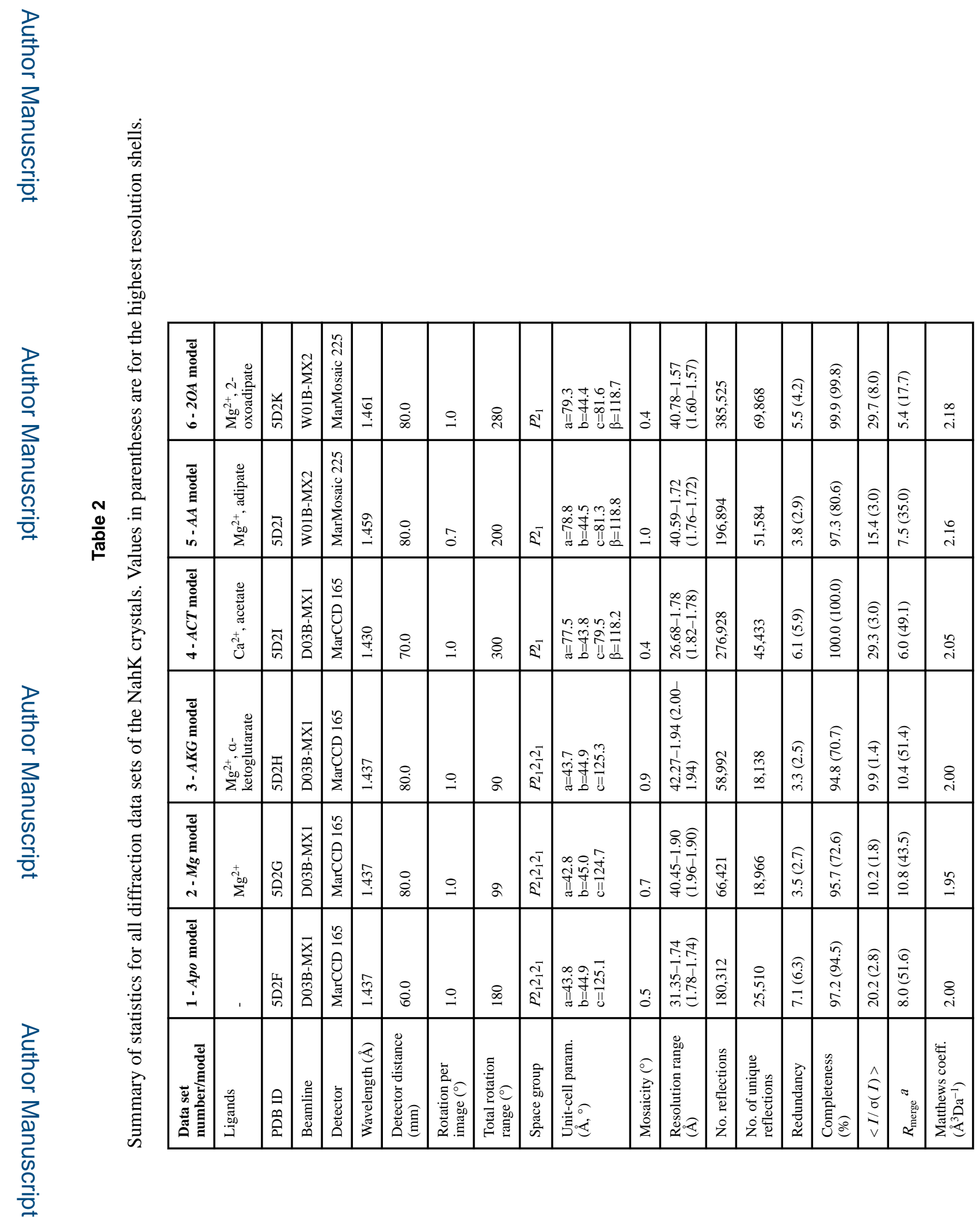

Biochemistry. Author manuscript; available in PMC 2016 May 10. 


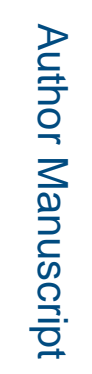

\begin{tabular}{|c|c|c|c|c|c|c|c|c|c|c|c|c|}
\hline 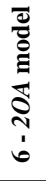 & $\underset{\dot{q}}{\stackrel{+}{ }}$ & $\begin{array}{l}\infty \\
\dot{\Xi}\end{array}$ & $\Xi$ & \begin{tabular}{l}
\multirow{2}{*}{} \\
o \\
\multirow{+}{*}{}
\end{tabular} & $\overline{6}$ & $\nabla$ & $\begin{array}{l}\infty \\
\stackrel{n}{n}\end{array}$ & $\stackrel{\text { ते }}{\text { in }}$ & 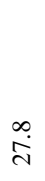 & $\stackrel{m}{I}$ & $\stackrel{\text { ò }}{.}$ & ¿े \\
\hline 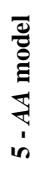 & $\overrightarrow{\mathscr{f}}$ & $\stackrel{t}{\sim}$ & $\vec{a}$ & $\begin{array}{l}\stackrel{\circ}{~} \\
\text { ले }\end{array}$ & $\stackrel{\sim}{n}$ & $\nabla$ & $\begin{array}{l}\infty \\
\infty \\
\infty\end{array}$ & $\begin{array}{l}\ddot{2} \\
\ddot{a}\end{array}$ & $\vec{\rho}$ & ָ̊ & है & 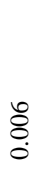 \\
\hline
\end{tabular}

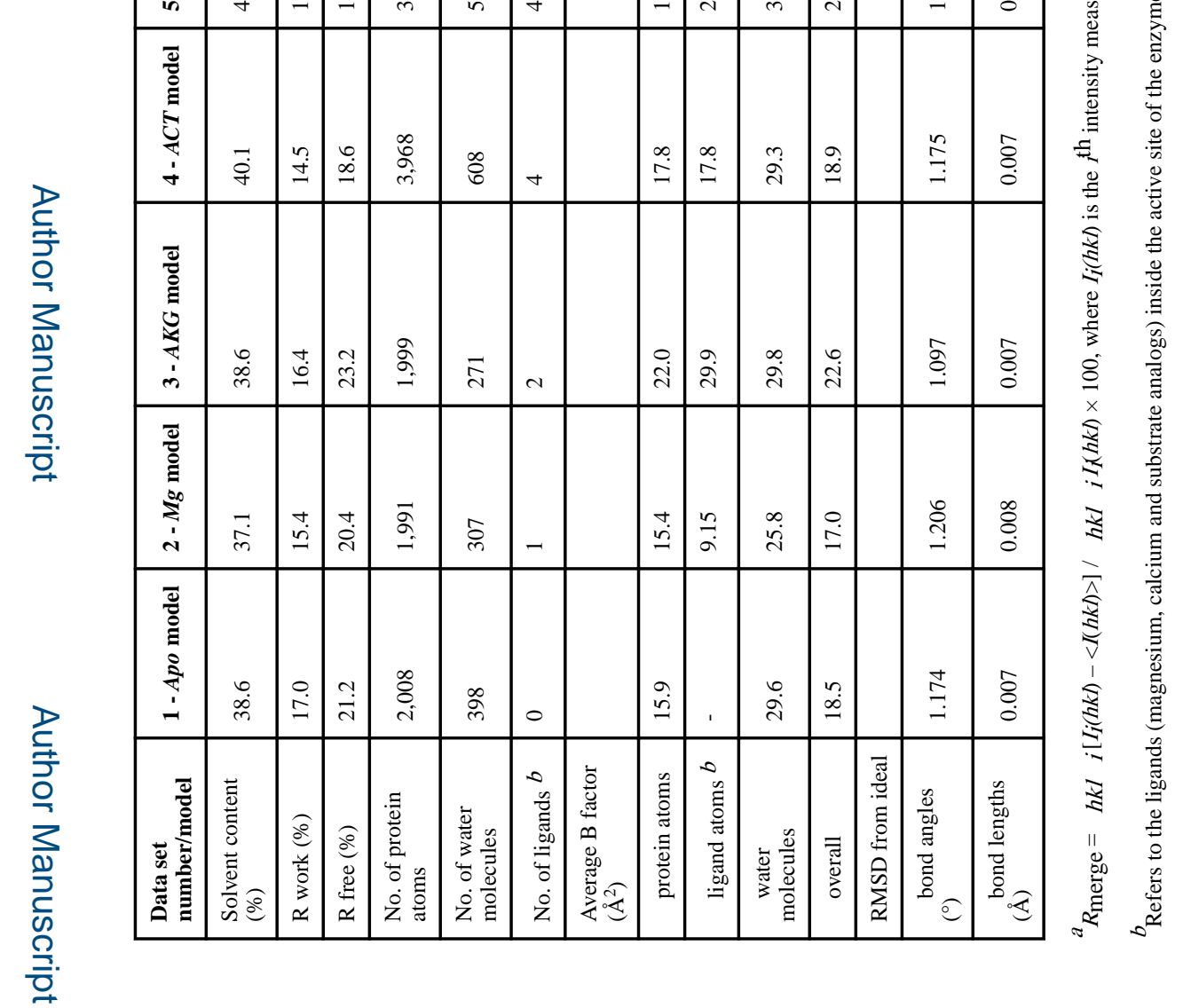

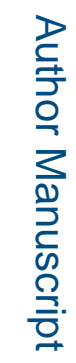




\section{Table 3}

Main polar interactions observed between the ligands and protein residues, metal ion and water molecules in the active site of NahK complexes.

\begin{tabular}{|c|c|c|}
\hline $\begin{array}{l}\text { Chain:Residue } \\
\text { [Atom] }\end{array}$ & $\begin{array}{l}\text { Distance } \\
(\AA)\end{array}$ & $\begin{array}{l}\text { Chain:Residue } \\
\text { [Atom] }\end{array}$ \\
\hline \multicolumn{3}{|l|}{ a-ketoglutarate } \\
\hline D:AKG [ O1 ] & 2.35 & $\mathrm{C}: \mathrm{MG} 1[\mathrm{Mg}]$ \\
\hline D:AKG [ O1 ] & 2.76 & A:LYS $64[\mathrm{~N} \zeta]$ \\
\hline D:AKG [ O3 ] & 2.98 & A:LEU 67 [ N ] \\
\hline D:AKG [ O5 ] & 2.81 & A:ALA 163 [ O ] \\
\hline D:AKG [ O2 ] & 2.50 & W:HOH 2 [ O ] \\
\hline \multicolumn{3}{|l|}{ Acetate } \\
\hline G:ACT 1 [ O ] & 2.36 & $\mathrm{C}: \mathrm{CA} 1[\mathrm{Ca}]$ \\
\hline G:ACT 1 [ O ] & 2.86 & A:LYS $64[\mathrm{~N} \zeta]$ \\
\hline G:ACT 1 [ OXT ] & 2.54 & W:HOH 2 [ O ] \\
\hline \multicolumn{3}{|l|}{ Adipate } \\
\hline D:0L1 [ O1 ] & 2.19 & C:MG 1 [ Mg ] \\
\hline D:0L1 [ O1 ] & 2.95 & A:LYS $64[\mathrm{~N} \zeta]$ \\
\hline D:0L1 [ O3 ] & 2.67 & A:SER $164[\mathrm{O} \gamma]$ \\
\hline D:0L1 [ O4 ] & 3.64 & A:LYS $72[N \zeta]$ \\
\hline D:0L1 [ O2 ] & 2.57 & W:HOH 2 [ O ] \\
\hline \multicolumn{3}{|l|}{ 2-oxoadipate } \\
\hline D:OOG 1 [ O1 ] & 2.09 & C:MG 1 [ Mg ] \\
\hline D:OOG 1 [ O3 ] & 2.20 & $\mathrm{C}: \mathrm{MG} 1$ [ Mg ] \\
\hline D:OOG 1 [ O1 ] & 2.74 & A:GLY 236 [ N ] \\
\hline D:OOG 1 [ O2 ] & 2.97 & A:LEU 67 [ N ] \\
\hline D:OOG 1 [ O3 ] & 2.75 & A:LYS $64[\mathrm{~N} \zeta]$ \\
\hline D:OOG 1 [ O4 ] & 2.79 & A:SER $164[0 \gamma]$ \\
\hline D:OOG 1 [ O5 ] & 2.71 & A:LYS $72[N \zeta]$ \\
\hline D:OOG 1 [ O2 ] & 2.67 & W:HOH $2[\mathrm{O}]$ \\
\hline
\end{tabular}

